\title{
Status Report on FY 2022 Model Development within the Integrated Energy Systems Hybrid Repository
}

December | 2021

Daniel Mikkelson

Konor L Frick

Amey Shigrekar

Shannon Bragg-Sitton

Idaho National Laboratory
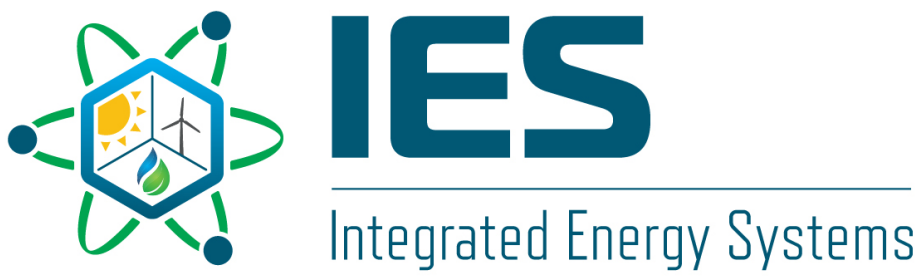


\section{DISCLAIMER}

This information was prepared as an account of work sponsored by an agency of the U.S. Government. Neither the U.S. Government nor any agency thereof, nor any of their employees, makes any warranty, expressed or implied, or assumes any legal liability or responsibility for the accuracy, completeness, or usefulness, of any information, apparatus, product, or process disclosed, or represents that its use would not infringe privately owned rights. References herein to any specific commercial product, process, or service by trade name, trade mark, manufacturer, or otherwise, does not necessarily constitute or imply its endorsement, recommendation, or favoring by the U.S. Government or any agency thereof. The views and opinions of authors expressed herein do not necessarily state or reflect those of the U.S. Government or any agency thereof. 
INL/EXT-21-65432

Revision 0

\title{
Status Report on FY 2022 Model Development within the Integrated Energy Systems Hybrid Repository
}

\author{
Daniel Mikkelson \\ Konor L Frick \\ Amey Shigrekar \\ Shannon Bragg-Sitton \\ Idaho National Laboratory
}

December 2021

Idaho National Laboratory Integrated Energy Systems Idaho Falls, Idaho 83415

http://www.ies.gov

Prepared for the U.S. Department of Energy Office of Nuclear Science Under DOE Idaho Operations Office

Contract DE-AC07-05ID14517 
Page intentionally left blank 


\section{ABSTRACT}

This publication details newly created energy storage models developed within the Hybrid Modelica repository as part of the Department of Energy's Office of Nuclear Energy (DOE-NE) Integrated Energy Systems (IES) program, led by Idaho National Laboratory (INL).

Model development to date includes creating dynamic systems-level models of a pebble-bed high-temperature gas reactor (HTGR), liquid air energy storage (LAES), and compressed air energy storage (CAES) in the IES-based Hybrid repository. Models are developed using the latest, publicly available data and incorporate the possibility of control strategy inclusion for use with the existing IES modeling, analysis, and optimization toolset. Simulations showcase the abilities of each technology to flexibly operate in ways consistent with IES operation expectations.

When these models are available, they can be utilized within different integrated energy park concepts to understand optimal system operation, control, and dispatching. Moreover, given the generic nature of the models, industrial partner technologies can be quickly added to the repository using the existing models as a basis. Additional dynamic models for thermal energy storage concepts can be developed and added to the Hybrid repository as needed. 
Page intentionally left blank 


\section{CONTENTS}

ABSTRACT

LIST OF ACRONYMS, INITIALISMS, AND ABBREVIATIONS.

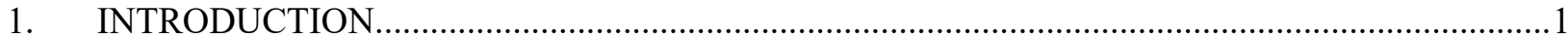

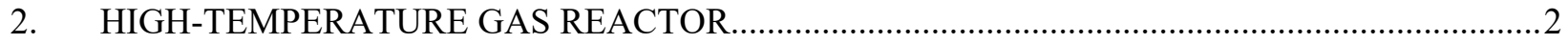

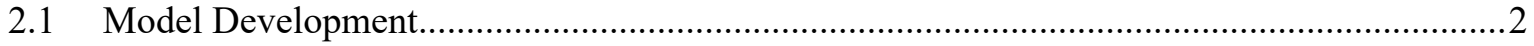

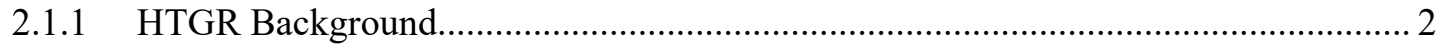

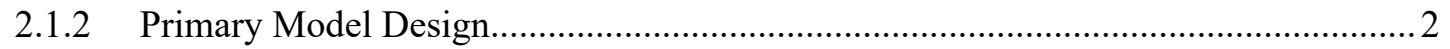

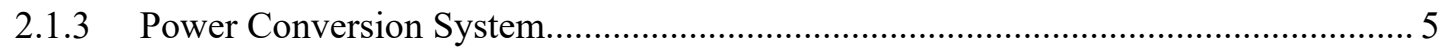

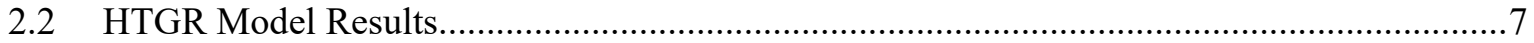

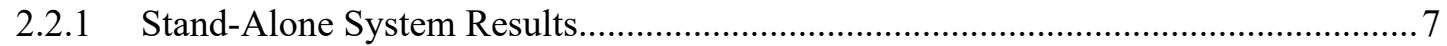

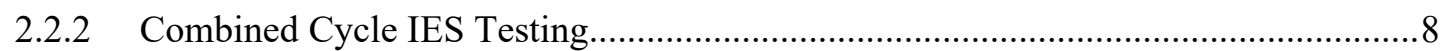

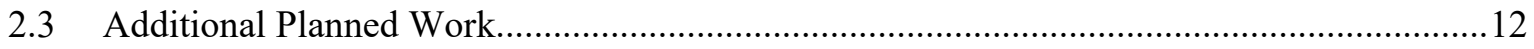

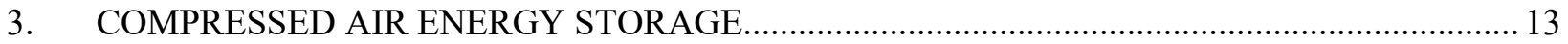

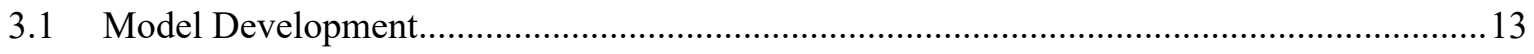

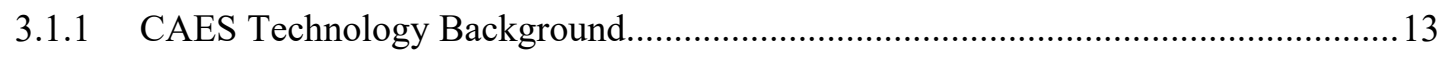

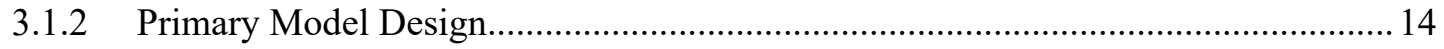

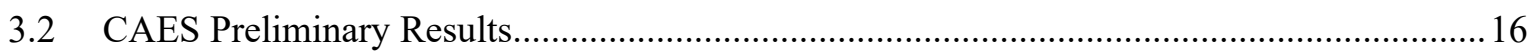

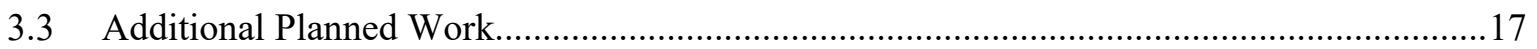

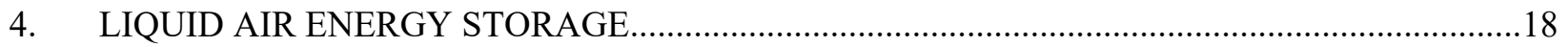

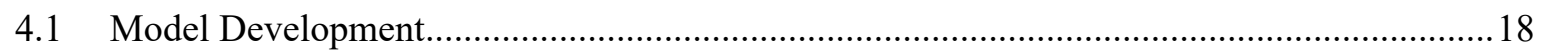

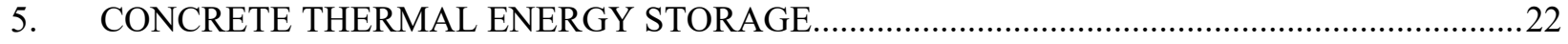

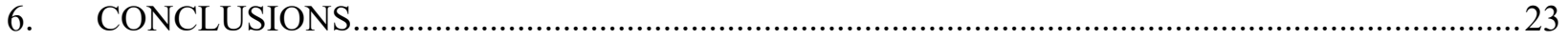

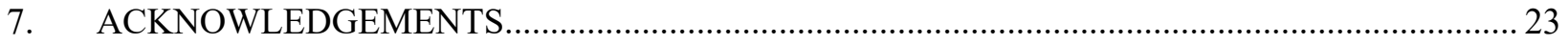

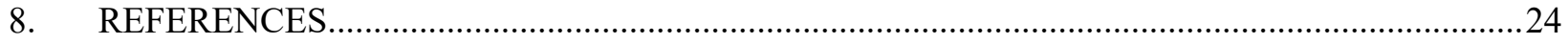

\section{FIGURES}

Figure 1. Example architecture for an Integrated Energy System................................................ 1

Figure 2. Fuel temperature reactivity coefficient curves from [4]............................................... 3

Figure 3. TRISO fuel structure within the Modelica framework...................................................4

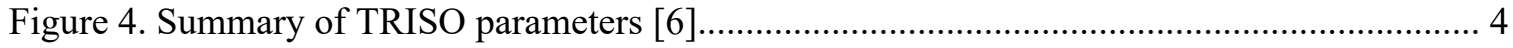

Figure 5. TRISO particle diagram [6]

Figure 6. Brayton cycle 600 MWt HTGR cycle diagram [7].................................................... 6

Figure 7. Integrable pebble-bed closed Brayton cycle HTGR with auxiliary heating capabilities.

Figure 8. Integrable pebble-bed closed Brayton HTGR at diagram level..................................... 7 
Figure 9. Evaluation of HTGR integration point with CTES peaking the steam portion of a

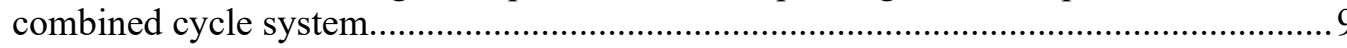

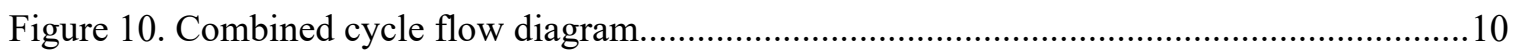

Figure 11. CTES temperatures in test case. Charging and discharging inlet and outlet

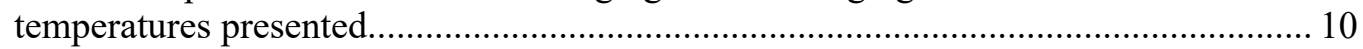

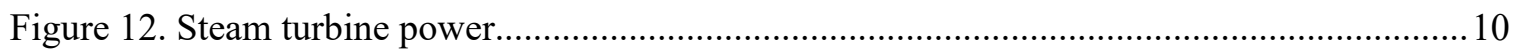

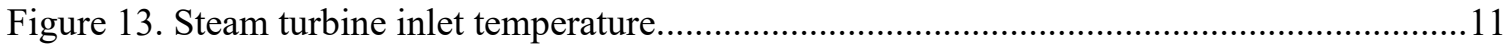

Figure 14. Power deposited (positive) or removed (negative) from the CTES during operation...11

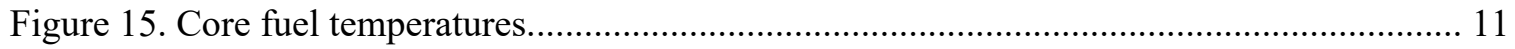

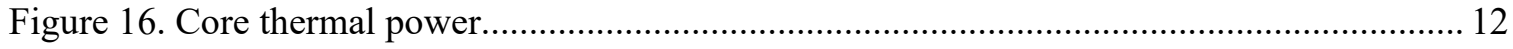

Figure 17. Reheater exit temperatures. The hot temperature is the core inlet temperature, while the reheater cold temperature becomes waste heat.........................................................12

Figure 18. Combined cycle and Brayton-only cycle system efficiencies..................................... 12

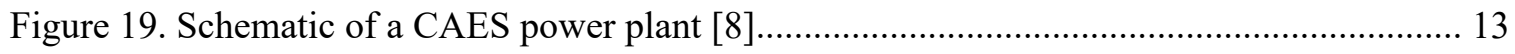

Figure 20. Compressor performance map with efficiency contours [10] .................................... 14

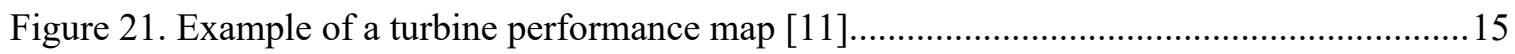

Figure 22. Simplified Modelica model of a CAES charging cycle.............................................. 16

Figure 23. Storage volume pressure, mass increase, and rate of change of mass flow.................. 16

Figure 24. Performance characteristics of compressor-pressure ratio, power, and applied torque.

Figure 25. High-level diagram of Highview Power LAES system............................................. 18

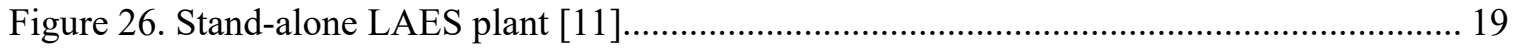

Figure 27. Charging loop including liquification and separation............................................... 20

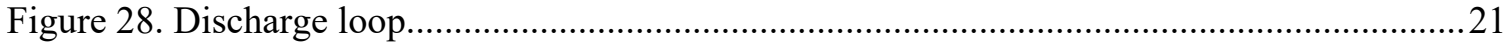

Figure 29. Thermal oil loop used to precondition air in both the charge and discharge cycle....... 22

Figure 30. Nodalization diagram of dual concrete model where one flow direction is indicated by the blue pipe and the other flow direction by the orange pipe. The single-pipe model

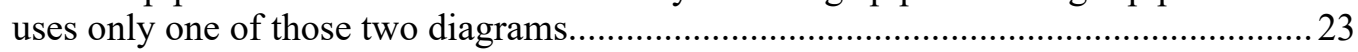

Figure 31. Square-grid configuration for single-network flow (left) and dual-network flow (right). Circles of same color indicate same flow direction. White square indicates section(s) modeled in Figure 30

\section{TABLES}

Table I. Closed-cycle model results comparison to reference publication 8 
Page intentionally left blank 


\section{LIST OF ACRONYMS, INITIALISMS, AND ABBREVIATIONS}

CAES Compressed-Air Energy Storage

CTES Concrete Thermal Energy Storage

DAE Differential Algebraic Equation

DOE-NE Department of Energy Office of Nuclear Energy

Dymola Dynamic Modeling Laboratory

ESGC Energy Storage Grand Challenge

FORCE Framework for Optimization of ResourCes and Economics

HTGR High-temperature Gas Reactor

IES Integrated Energy Systems

INL Idaho National Laboratory

LAES Liquid Air Energy Storage

M\&S Modeling and Simulation

ORNL Oak Ridge National Laboratory

RD\&D Research, Design, and Development

RTE Round Trip Efficiency

TES Thermal Energy Storage

TRISO Tri-structurial isotropic particle 


\section{INTRODUCTION}

The need for modernization within the electrical grid has become a national and global priority. Domestically, the Department of Energy (DOE) has developed a program, the Energy Storage Grand Challenge (ESGC), to "accelerate the development, commercialization, and utilization of next-generation energy storage technologies and sustain American global leadership in energy storage." [1] The program's aggressive goal is to develop storage technologies to meet all market demands by the year 2030 [1]. The ability to store thermal, electrical, and chemical energy at the grid-participant level will allow for energy producers to more dynamically allocate their energy as needed across multiple applications. For some resources, this paradigm shift would lead to continuous energy application despite intermittent generation, and for some, the inverse could happen where energy is stored up during continuous generation to be applied later in batches. In either case, innovations in electrical, mechanical, thermal, chemical, and electro-chemical energy storage technologies will be necessary to provide the most flexibility economically, environmentally, and for safety.

The Department of Energy's Office of Nuclear Energy (DOE-NE) Integrated Energy System (IES) program is led by Idaho National Laboratory (INL). The program continues to lead research, design \& development (RD\&D) efforts to determine technology candidates, integration techniques, analysis methods, and produce analytic tools. Because IES increases the number of markets in which energy producers and users can consume or direct energy streams, traditional methods that analyze stand-alone systems are no longer sufficient. Developing new tools that can incorporate novel control strategies, balance complex production and demand systems that may include memory, and operate within multiple systems' safety limits requires significant architecture development. An example potential IES that integrates power generators, hydrogen production, the electrical grid, and multiple hydrogen users is shown in Figure 1.

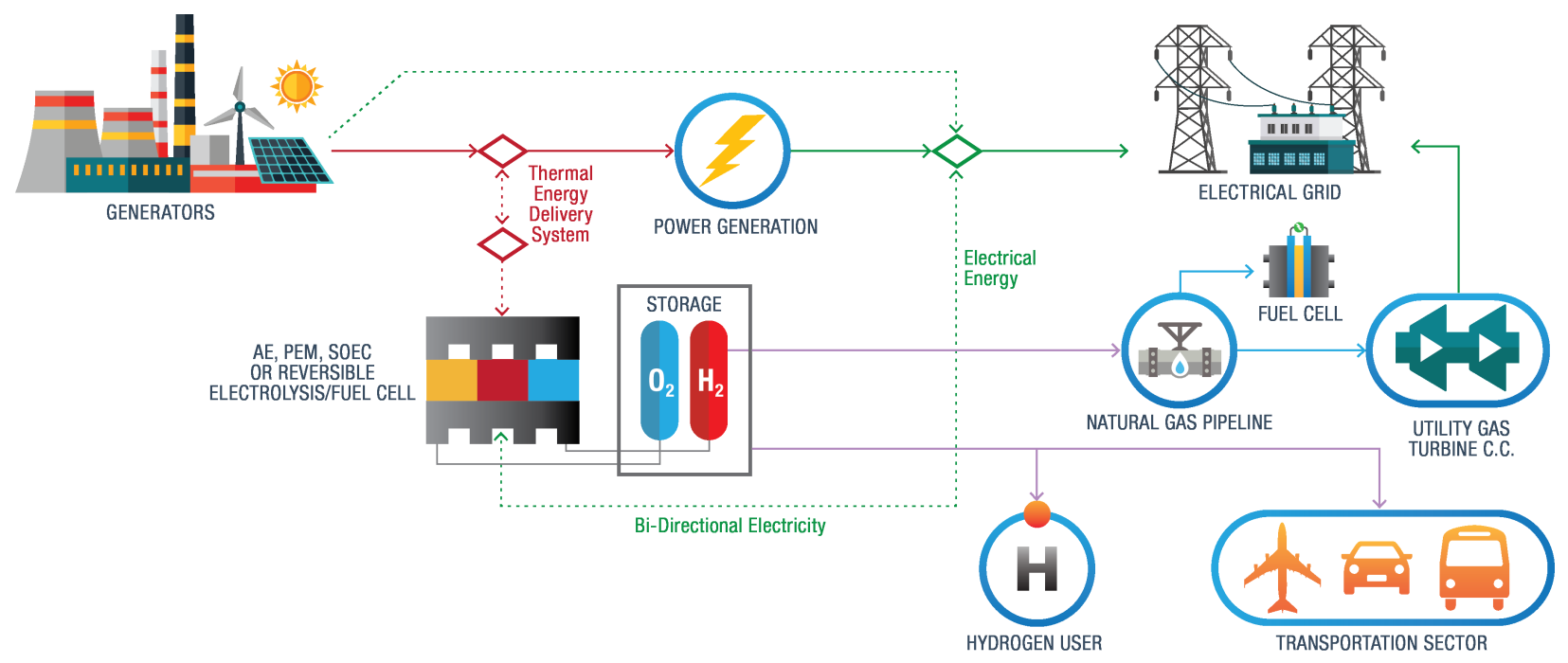

Figure 1. Example architecture for an IES.

One component of the IES architecture under development at INL is Hybrid, a Modelica library of high-fidelity process models in the Modelica modeling language. Hybrid is one analytic tool that will be integrated into the Framework for Optimization of ResourCes and Economics (FORCE) analysis framework. The Modelica language is a non-proprietary, object-oriented, and equation-based language used to conveniently model complex, physical systems. Modelica is an inherently time-dependent modeling language that allows the swift interconnection of independently developed models. Being an equation-based modeling language that employs differential algebraic equation (DAE) solvers, users can focus on the physics of the problem rather than the solving technique, allowing faster model generation and, ultimately, analysis. This feature, alongside model flexibility, has led to the widespread use of the 
Modelica language across industry for commercial applications. System interconnectivity and the ability to quickly develop novel control strategies while still encompassing overall system physics is why INL has chosen to develop the IES framework in the Modelica language.

Current models in the INL Hybrid repository include four-loop light-water-cooled nuclear power plants, natural circulation small modular reactors, natural gas turbines, coal plants, switchyards, hightemperature steam electrolysis, reverse osmosis, electric grid models, concrete thermal energy storage, two-tank sensible heat thermal energy storage, thermocline energy storage, and batteries. The INL repository also includes some IES examples using the developed models. A consistent structure is used throughout to facilitate control strategy studies.

This report details ongoing model development that supports IES research. As the IES program looks forward, support for advanced reactors and a wide variety of energy storage technologies will be needed. Models presented in this report include a high-temperature gas reactor (HTGR), compressed air energy storage (CAES), and liquid air energy storage (LAES). A brief update on the concrete thermal energy storage model is also included. All models have been implemented using the commercially available Modelica-based Modeling and Simulation (M\&S) environment (i.e., a Dynamic Modeling Laboratory Dymola version 2021x or 2022) [2, 3]. In-house developed packages and opensource libraries were utilized to facilitate M\&S. In particular, the Modelica standard library version 4.0 and the Transient Simulation Framework of Reconfigurable Models (TRANSFORM) from Oak Ridge National Laboratory (ORNL) [4].

\section{HIGH-TEMPERATURE GAS REACTOR}

\subsection{Model Development}

\subsubsection{HTGR Background}

HTGRs are designated as an advanced reactor, but their roots date back decades. Operating HTGRs keys off a different fuel type than the ceramic pellets encased in fuel rods with which light-water reactors operate. Tri-structural isotropic particle (TRISO) fuel has a very high melting point that allows for HTGR operation to be considered meltdown-proof. TRISO fuel builds around a fuel kernel and a 5-layer small bead which are placed in large numbers into one of the two fuel designs: prismatic rods or pebbles. The fuel element of the kernel is either UO2 or UCO. Surrounding the fuel element is a series of carbon-based layers designed to prevent the release of fission product gases during operation.

Two primary fuel configurations in HTGR designs are the pebble-bed and prismatic-fuel design. Both use TRISO fuel and have similar operating temperatures, but the fuel management techniques are very different. Pebble-bed reactors use fuel "pebbles" that move through the core to produce power. The pebble is around $6 \mathrm{~cm}$ in diameter and contains on the order of 10,000 fuel kernels suspended in a graphite network. Tens to hundreds of thousands of these pebbles make up a core. They are inserted via the top of the core and removed through the bottom using a fuel management system while the reactor is operating. This online refueling allows for nearly identical conditions across cycle lifetime. Prismatic-fuel design is similar to existing reactor technologies with rods moving in bundles during outages.

\subsubsection{Primary Model Design}

The most distinct HTGR design model is the reactor core model. To produce the core model, the coolant flow model, kinetics model, and fuel models must interact to calculate power, coolant, and fuel conditions in the core.

The most common coolant type observed in the literature is helium. Helium is used as it is a common, inert, and low cross-section material. Helium has no potential chemical reactions with fuel or fission products and thus does not introduce any exothermic risks similar to water-cladding reactions that can exist. Because of the low cross-section of He, neutron moderation occurs in HTGR cores in reflector blankets primarily made of graphite. Because of the coolant and neutron moderator's separation, there is little neutron feedback in the core due to the conditions of the coolant (unlike in water operations). The 
Modelica standard library contains a helium-gas package that is usable with Hybrid components.

The heat transfer coefficient is calculated using the Dittus-Boelter correlation. As helium is always a single phase, there is no need to use two-phase capable correlations. The cross-sectional flow area assumes that the pebbles are in a perfectly settled contact such that the flow area for a given channel is effectively the same as a square-set fuel rod if the rod diameter and rod pitch were the same. This method is used for two reasons. First, the rod configuration is well-proven to work within the Hybrid framework. Second, this assumption is not far from reality if we consider that a particular molecule of coolant should always be able to see pebbles arranged like this as it flows through the core.

Because the role of coolant and moderator are separated by the use of helium, there is only one feedback coefficient included in the reactor kinetics model. The fuel feedback coefficient is found in literature [4], seen in Figure 2. As of right now, the model uses a constant feedback coefficient that is about the average value in the expected $800-1200$ typical range: $-5.0 \mathrm{pcm} / \mathrm{K}$. Reduced natural feedback mechanism increases the importance and need for control rod methods to maintain key system values.

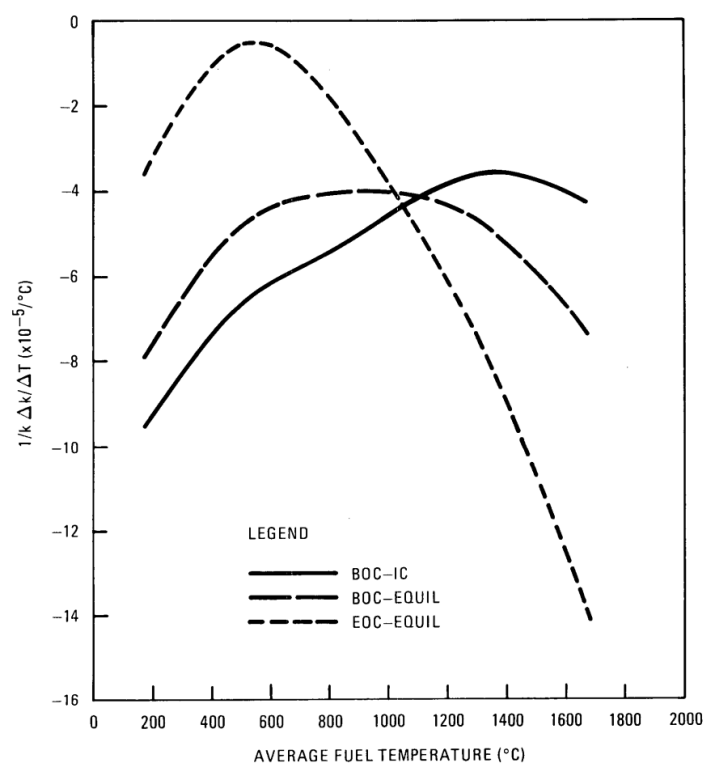

Figure 2. Fuel temperature reactivity coefficient curves from [4].

TRISO fuel is built as a multilayer concentric sphere with constant thermal conductivity in the various non-fuel layers, seen in Figure 3. Power is assumed to be produced at a constant rate volumetrically within the spherical fuel kernel. Using Dymola heat ports, power is balanced between the layers, and the temperatures at the interfaces are set to be equal. The primary modeling question of modeling the fuel kernel is: what is the kernel surface temperature? This boundary condition is a necessary to determine the effective and centerline fuel temperatures. 


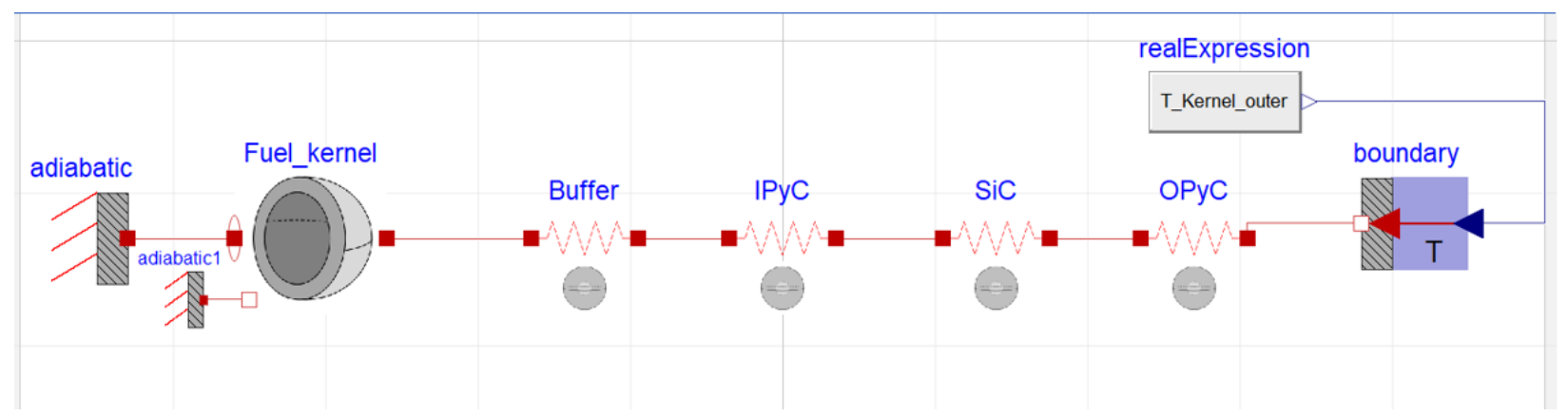

Figure 3. TRISO fuel structure within the Modelica framework.

To calculate the kernel outer temperature, the fuel pebble is modeled as a solid sphere with a uniform power production. TRISO kernels are randomly distributed throughout the sphere. An average location within the pebble is calculated as the kernel surface temperature. By maintaining a fuel kernel with a number of radial nodes equal to the denominator of our power fraction, we can find one of the nodes that has the appropriate kernel surface temperature. The centerline temperature can simply use the pebblecentral port or adiabatic boundary-condition port temperature as the surface temperature. A second iteration of the fuel model calculates the fuel centerline temperature in the same way as the average fuel model.

\begin{tabular}{|c|c|c|}
\hline Attribute & Units & Value \\
\hline Irradiation duration & Effective Full Power Days & 400 \\
\hline End-of-life burnup & $\%$ FIMA & 16 \\
\hline End-of-life fluence & $10^{25} \mathrm{n} / \mathrm{m}^{2}\left[\mathrm{E}_{\mathrm{n}}>0.18 \mathrm{MeV}\right]$ & 5 \\
\hline \multirow{2}{*}{ Irradiation temperature } & \multirow{2}{*}{ 然 } & 1173 (Low) \\
\hline & & 1573 (High) \\
\hline Ambient pressure & $\mathrm{MPa}$ & 0.1 \\
\hline Kernel diameter & $\mu \mathrm{m}$ & $425 \pm 10$ \\
\hline Buffer thickness & $\mu \mathrm{m}$ & $100 \pm 10$ \\
\hline IPyC thickness & $\mu \mathrm{m}$ & $40 \pm 4$ \\
\hline SiC thickness & $\mu \mathrm{m}$ & $35 \pm 3$ \\
\hline OPyC thickness & $\mu \mathrm{m}$ & $40 \pm 4$ \\
\hline Particle asphericity & & $1.04 \pm 0.02$ \\
\hline Kernel density & $\mathrm{Mg} / \mathrm{m}^{3}$ & 11.00 \\
\hline Buffer density & $\mathrm{Mg} / \mathrm{m}^{3}$ & 1.04 \\
\hline IPyC density & $\mathrm{Mg} / \mathrm{m}^{3}$ & $1.90 \pm 0.02$ \\
\hline OPyC density & $\mathrm{Mg} / \mathrm{m}^{3}$ & $1.90 \pm 0.03$ \\
\hline IPyC BAF & & $1.04 \pm 0.005$ \\
\hline OPYC BAF & & $1.03 \pm 0.005$ \\
\hline U-235 enrichment & Weight \% & 15.50 \\
\hline Oxygen-to-uranium & Atom Ratio & 1.50 \\
\hline Carbon-to-uranium & Atom Ratio & 0.39 \\
\hline
\end{tabular}

Figure 4. Summary of TRISO parameters [6]. 


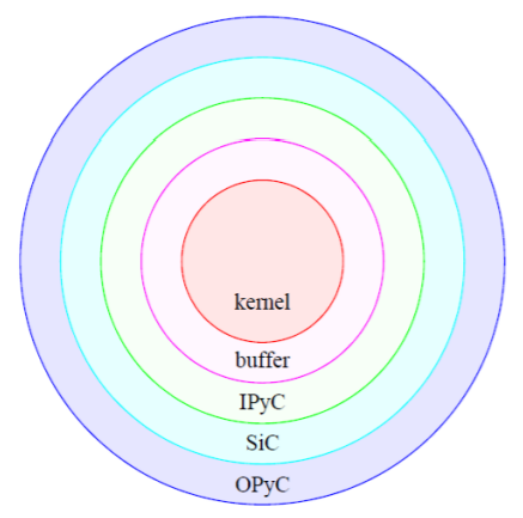

Figure 5. TRISO particle diagram [6].

The core model connects to a fluid network that allows fluid flow into the power conversion system. The power conversion system models will then calculate all downstream conditions and return the coolant inlet conditions to the core model.

\subsubsection{Power Conversion System}

Power conversion systems in HTGR designs can operate in three ways. Brayton cycle systems directly or indirectly use helium to power a gas turbine. In the direct system, the helium expands through the turbine and goes through multiple stages of cooling and compression before reentering the core. In Rankine systems, the coolant is passed through a steam generator to boil water to then send through steam turbines. In this system, the coolant machinery is simpler as only a simple blower system is required to maintain the required mass flow rate. The final possible cycle is a combined cycle system in which the effective waste heat from the Brayton cycle is used to boil water and turn a steam turbine.

A Brayton cycle in an HTGR is a closed loop cycle. The coolant that flows through the turbine and compressors is the same coolant that flows through the core. The coolant flows out of the core and directly to the turbine. At the outlet of the turbine, a heat recuperator removes much of the heat of the coolant. The HTGR model contains a two-stage cooling-compression process to bring the coolant pressure back up to reactor pressure. System pressure control is linked in downstream of the first cooler at the mixture of coldest and lowest pressure point in the loop. Two-way pressure control is implemented via a valve and a pressure boundary. After the second compressor stage, the coolant passes through the reheater on the cold side, recovering the heat from the fluid exiting the turbine. Net electric power is calculated as the difference between the turbine output and compressor inputs.

The current simple control system moves control rods based solely on the output temperature of the core. A mass flow controlling mechanism needs to be introduced in some manner. Current output matches well with the flow diagram in Figure 6 [7]. 


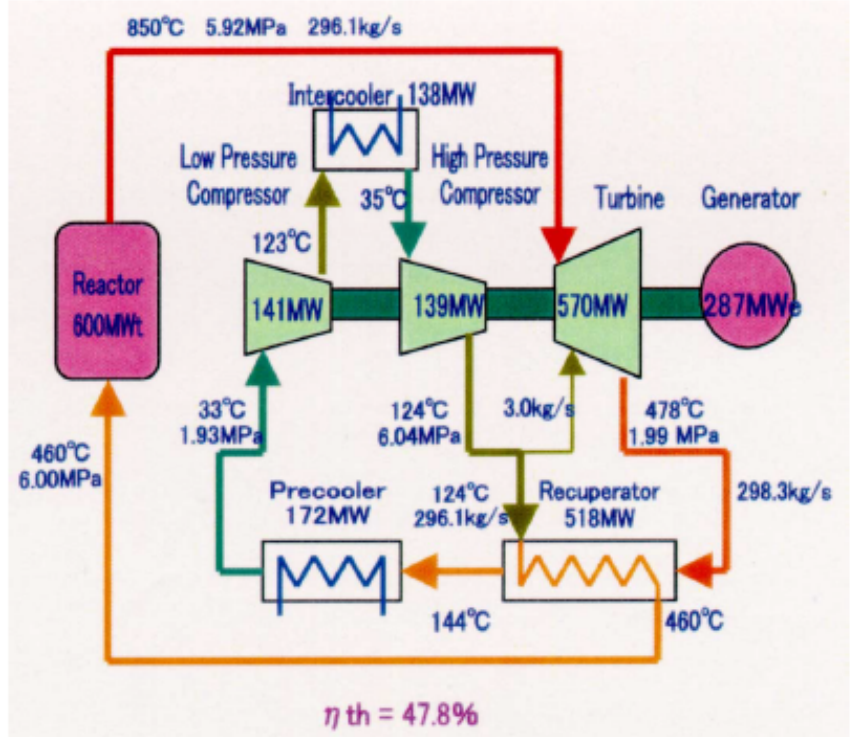

Figure 6. Brayton cycle 600 MWt HTGR thermodynamic diagram [7].

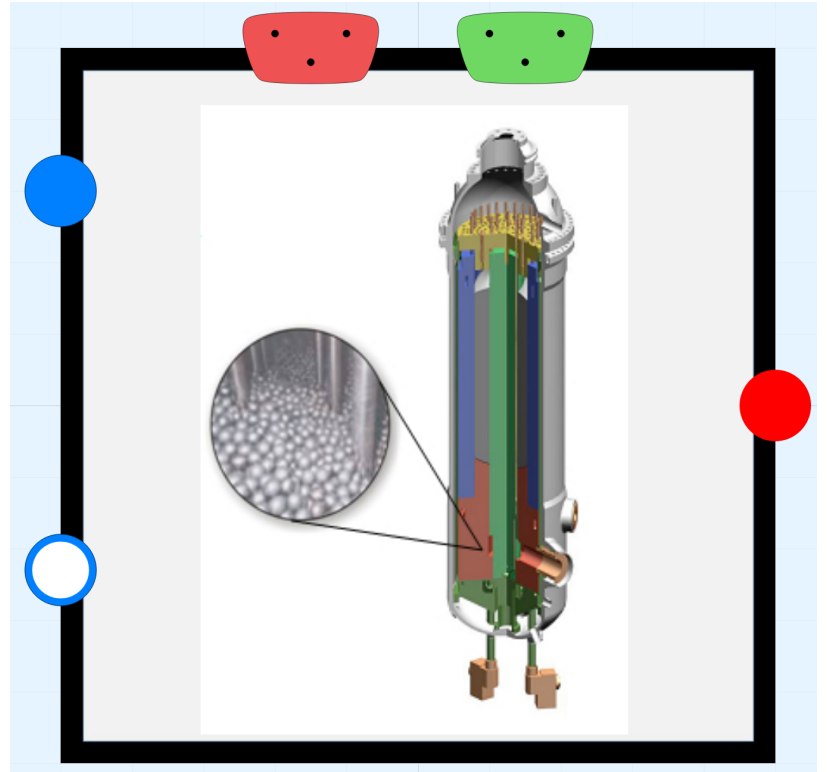

Figure 7. Integrable pebble-bed closed Brayton cycle HTGR with auxiliary heating capabilities. 


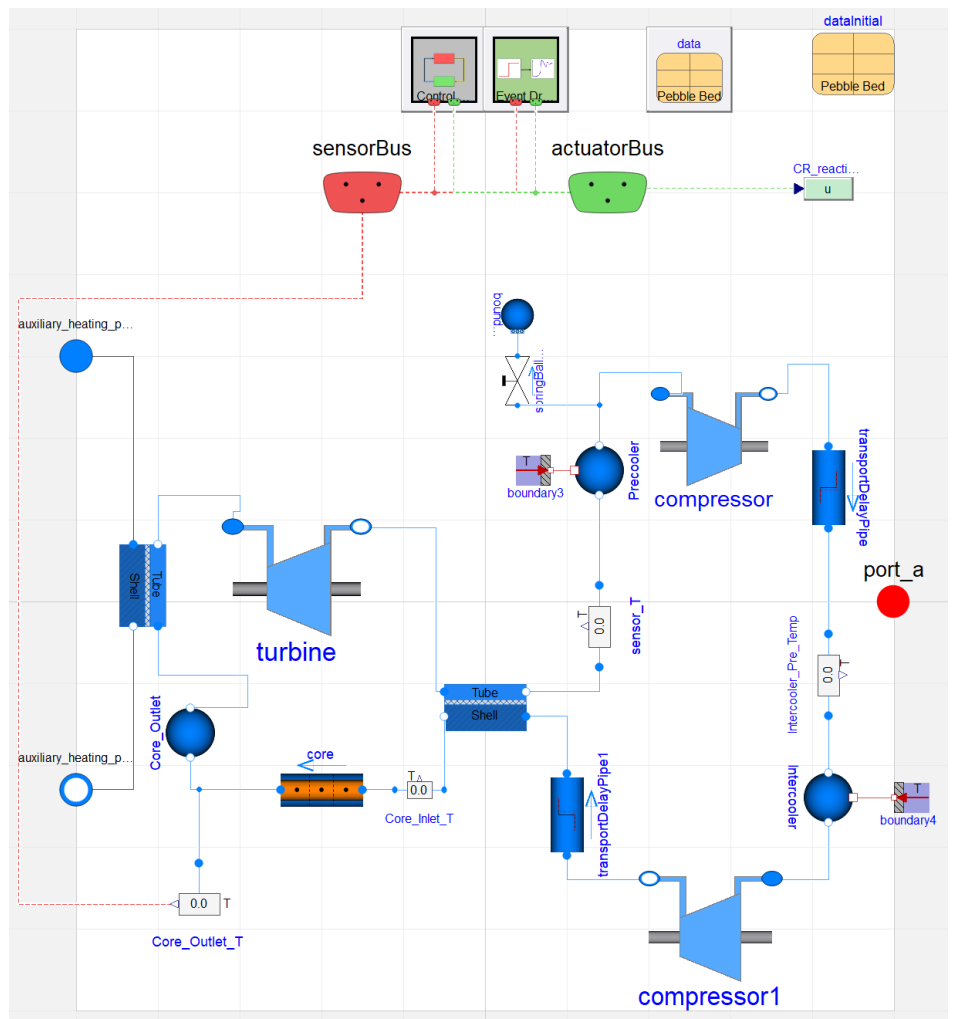

Figure 8. Integrable pebble-bed closed Brayton HTGR at diagram level.

In a Rankine cycle system, the HTGR coolant is blown through the core and into a He-water heat exchanger. The water is boiled on the other side and is directed to a steam turbine to produce power. In this case, the helium components are simpler than in the Brayton cycle. The coolant path exits the core and is directed to the heat exchanger. After that, the cold fluid is cycled around using a blower, which is similar to a compressor in function but uses significantly less power (as the only system pressure losses are from local losses and friction). As of this writing, only the Rankine cycle system has not been fully developed.

To make a combined cycle system, two heat exchangers are added to the Brayton cycle system. Each is inserted just upstream of the coolers in front of the compressors. In this manner, heat that would previously have been wasted is instead used to boil relatively low-pressure water. This steam is then directed to a small steam turbine to produce additional power.

The IES team at INL, and most modelers of HTGRs since few are built, need to work with new models to determine the kinds of integration techniques most appropriate to maintain system efficiency. The Hybrid set of tools should be able to inform researchers about the advantages or disadvantages of various integration points along with which cycle is more appropriate for IES use.

\subsection{HTGR Model Results}

\subsubsection{Stand-Alone System Results}

Figure 6 was used to build the first closed-cycle Brayton HTGR system in Modelica, seen in Figure 8. To ensure some proper control in the reactor, there are four setpoints. The first setpoint is the system pressure, controlled by a spring-type valve that opens when there is an excess pressure on the inlet. The pressure is set at 19.3 bar just upstream of the first compression stage. The second setpoint is the reactor exit temperature. The control rods move in or out of the core to control the core exit temperature at $850^{\circ} \mathrm{C}$. The third and fourth setpoints are the precooler and intercooler temperatures. Temperature 
boundary conditions set these temperatures in the flow volumes. These steady-state results are presented in Table I.

Table I. Closed-cycle model results comparison to reference publication.

\begin{tabular}{|l|l|l|}
\hline Parameter/Value & Reference Value & Simulation Value \\
\hline Core Thermal Power & $600 \mathrm{MW}$ & $611 \mathrm{MW}$ \\
\hline Turbine Power & $570 \mathrm{MW}$ & $576.5 \mathrm{MW}$ \\
\hline Compressor 1 Power & $141 \mathrm{MW}$ & $137.3 \mathrm{MW}$ \\
\hline Compressor 2 Power & $139 \mathrm{MW}$ & $138.2 \mathrm{MW}$ \\
\hline System Mass Flow Rate & $296.1 \mathrm{~kg} / \mathrm{s}$ & $298.706 \mathrm{~kg} / \mathrm{s}$ \\
\hline Core Inlet Temperature & $460^{\circ} \mathrm{C}$ & $456.22^{\circ} \mathrm{C}$ \\
\hline Core Pressure & $60 \mathrm{bar}$ & $59.8 \mathrm{bar}$ \\
\hline Turbine Outlet Pressure & $19.9 \mathrm{bar}$ & $19.7 \mathrm{bar}$ \\
\hline Compressor 1 Outlet Pressure & N/A & $34.0 \mathrm{bar}$ \\
\hline $\begin{array}{l}\text { Average Fuel Temperature at } \\
\text { Core Node 2 of 4 }\end{array}$ & N/A & $868.8^{\circ} \mathrm{C}$ \\
\hline
\end{tabular}

Model results are consistent with the reference system diagram. Various parameters, including the heat exchanger effectiveness, turbine and compressor efficiencies, reference flow rates, pressure loss coefficients, and reference pressure ratios can all be tuned to match the reference design when necessary. The primary goal at this stage of system modeling is to have results that indicate model consistency with accepted values.

\subsubsection{Combined Cycle IES Testing}

To continue gaining knowledge of how an HTGR may be placed into an IES, a test was built to evaluate a potential IES integration point. The combined cycle HTGR model in Hybrid uses decay heat to produce steam to send to an external steam turbine. The test evaluates integrating an IES integration point upstream of the gas turbine to produce additional steam to heat a CTES. The outer test diagram is seen in Figure 9. The left fluid ports show a cyclical steam offtake fluid source that then rejects to one side of the CTES model. The standard combined cycle water enters in the bottom right fluid port with a constant flow rate and condition, is heated by the waste heat in the HTGR, and returns to the outer model via the left bottom-side fluid port. This steam is always sent through the CTES before producing power via the steam turbine. 


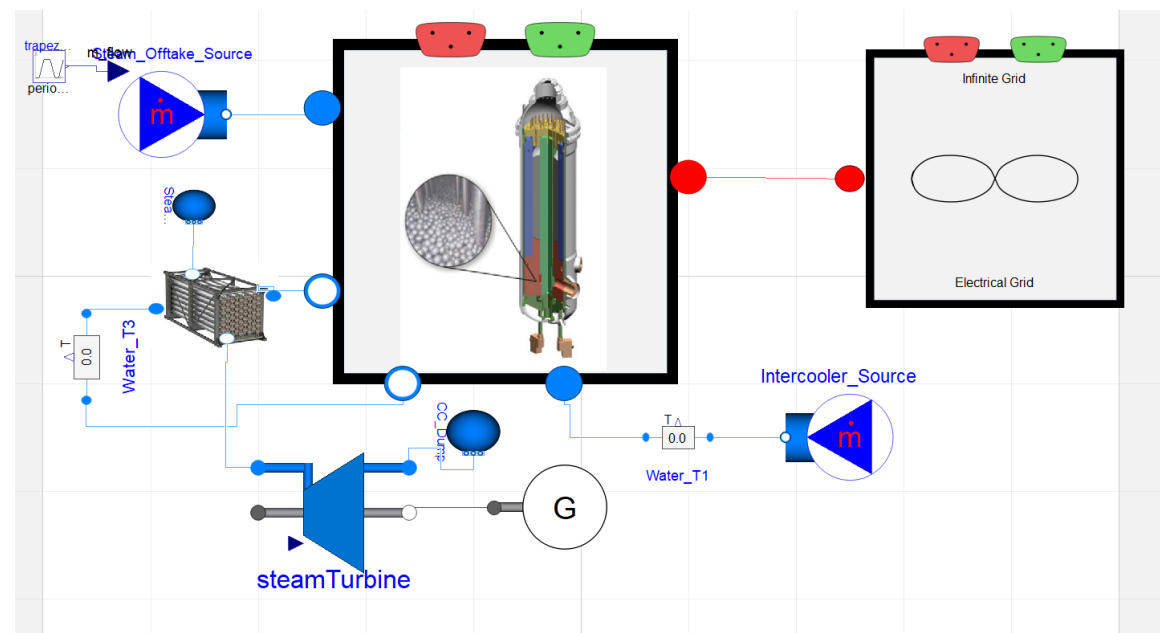

Figure 9. Evaluation of HTGR integration point with CTES peaking the steam portion of a combined cycle system.

Figure 10 shows the full system diagram. The auxiliary and cyclical steam heating occurs upstream of the gas turbine, as shown. The standard combined cycle heat is applied in the "Waste_Heat_Vol" via applied equations and via the heat exchanger furthest on the right in the diagram. This test is designed to evaluate whether cyclical storage can provide a power boost to the combined cycle.

The simulation shows the end of one cycle and then two more subsequent cycles before no additional charging occurs in the final half of the simulation. The goal of ending the charging cycles is to clarify the impact of the CTES on the steam power production. Figure 11-Figure 14 demonstrate the impact of the charging cycles in the CTES system. Note the charging mass flow rate was scaled to make sure that during cyclical operation the concrete, temperature did not exceed $400^{\circ} \mathrm{C}$, which begins to be dangerous for concrete systems. By looking at Figure 12 and Figure 13, it does not appear that the CTES boosting is changing the steam temperature entering the steam turbine or the turbine power output. The turbine power changes by less than $100 \mathrm{~kW}$ even with the addition of heat into the CTES from the HTGR. Figure 14 demonstrates that the contributed heat to the steam system is quite steady, which is typical of dualnetwork CTES. 


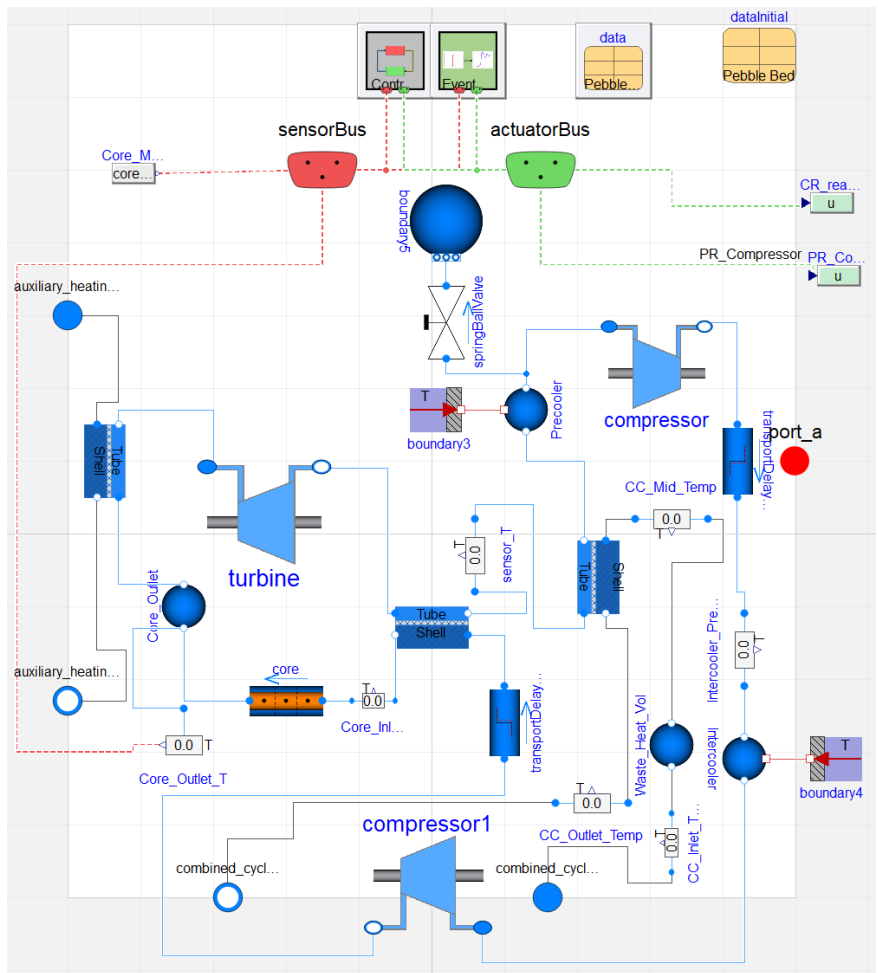

Figure 10. Combined cycle flow diagram.

The impact on concrete system temperatures can be seen in at the beginning of Figure 11.

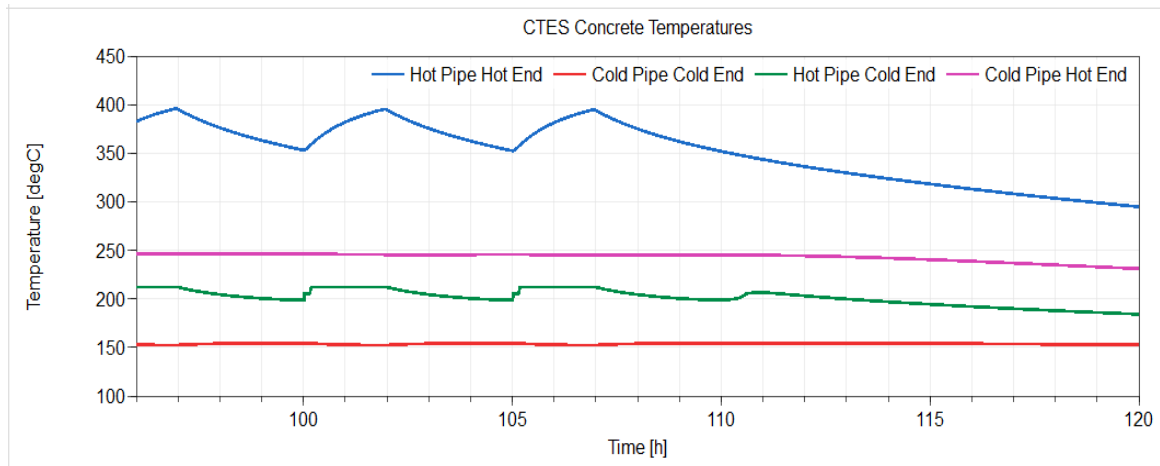

Figure 11. CTES temperatures in test case. Charging and discharging inlet and outlet temperatures presented.

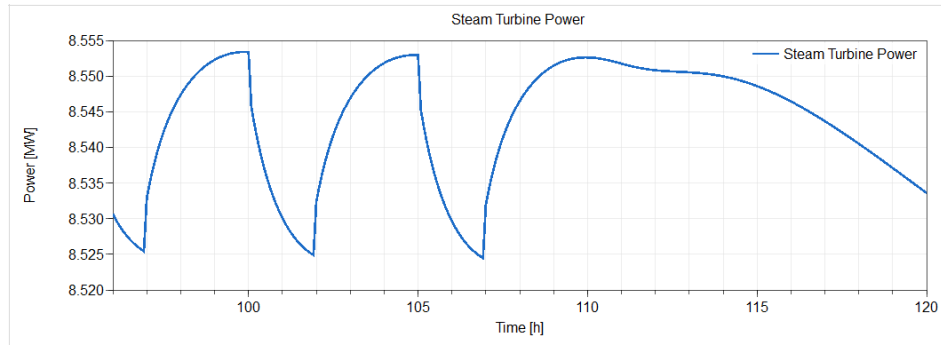

Figure 12. Steam turbine power. 


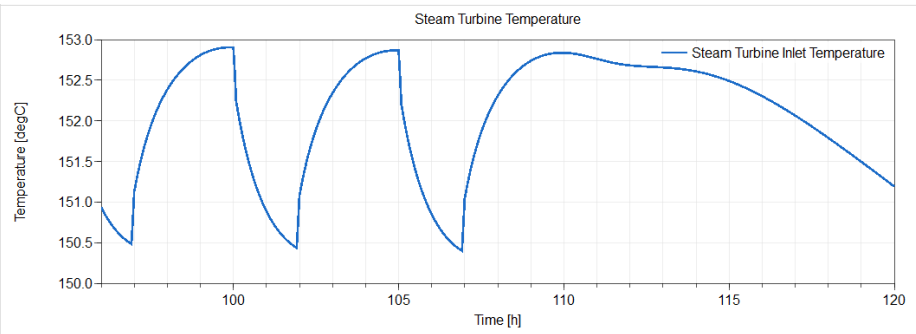

Figure 13. Steam turbine inlet temperature.

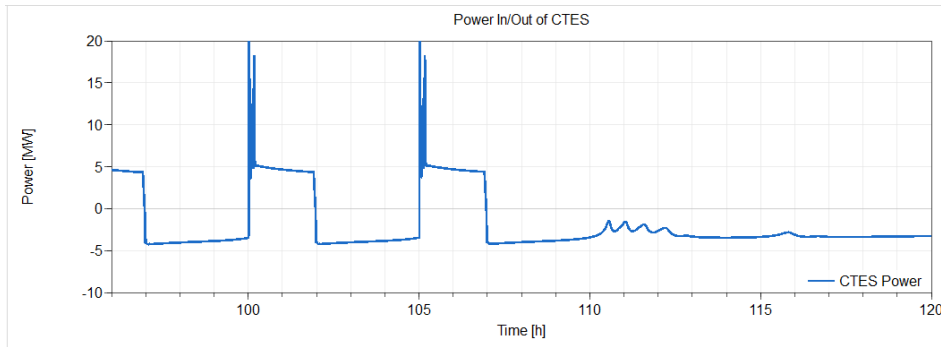

Figure 14. Power deposited (positive) or removed (negative) from the CTES during operation.

Figure 15 shows little temperature change in the core due to the transients. It is interesting to note that some of the fuel temperatures increase while others decrease during extra heat offtake. Fuel near the exit of the core rises in temperature (red and blue lines) as the core power increases, seen in Figure 16, to maintain a constant coolant exit temperature. The control rods withdraw. Closer to the core inlet, the fuel temperature decreases despite the power increase because the inlet coolant temperature has decreased, and that change propagates through to the fuel temperature. The drop in inlet coolant temperature is observed in Figure 17, which shows the outlet temperature of the reheater element in the HTGR cycle. Because the helium conditions exiting the high-pressure compressor are effectively constant, the helium exiting the reheater is cooled to a nearly constant condition as well. However, the removal of heat before the turbine cooled the turbine exit conditions, leading to less heating of the helium about to enter the core.

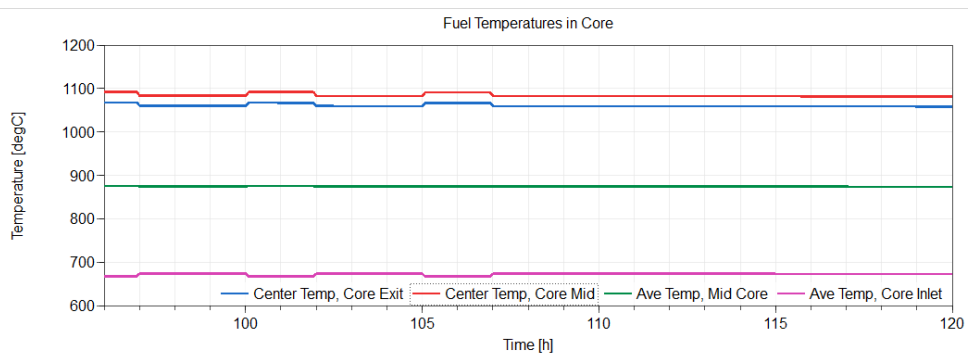

Figure 15. Core fuel temperatures. 


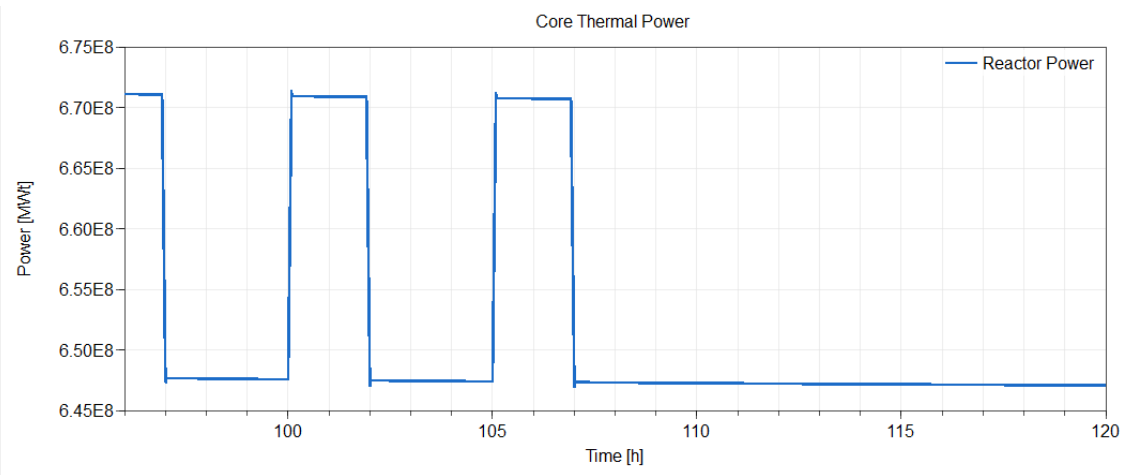

Figure 16. Core thermal power.

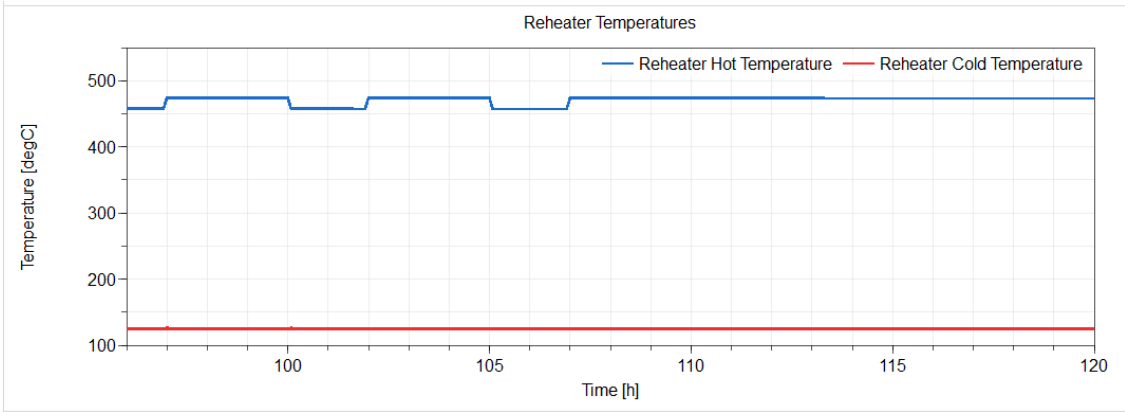

Figure 17. Reheater exit temperatures. The hot temperature is the core inlet temperature, while the reheater cold temperature becomes waste heat.

Overall, the impact of running the CTES steam temperature topping cycle does not appear to have much impact on the overall system efficiency. The blue line extending to the right is completely flat. The overall system efficiency impact is not small during charging though, as the thermal power must increase to maintain helium conditions.

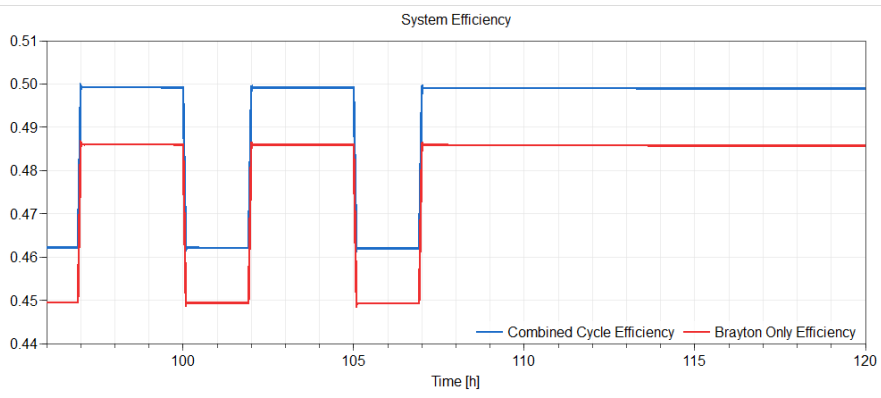

Figure 18. Combined cycle and Brayton-only cycle system efficiencies.

The combined cycle HTGR model allowed for the investigation into an integrated system using a specific integration point and control scheme. In this case, the results showed that using CTES as a buffer superheating steam directed to a steam turbine is not viable and results in large system penalties without corresponding gains. At the same time, this case study does show that the models exhibit system feedback in ways that make physical sense.

\subsection{Additional Planned Work}

Additional planned work can be separated into two main categories: improvement and expansion.

To improve the models, additional information is needed. While these models can be tuned to exhibit the steady-state values found across different designs in literature, it is difficult to ascertain their accuracy 
in dynamic situations. To improve confidence in dynamic situations, additional expert knowledge regarding some of the physical aspects of HTGRs is required to improve models. Specifically, physical dimensions and system mass are necessary for accurate feedback time scales. Some dynamic estimations from outside sources may be available for Rankine systems. Additionally, confirmation of reactor kinetics with more up-to-date information is key to improve confidence in these models.

Expansion includes adding a new core model that reflects a prismatic core instead of a pebble-bed core. The fuel model specifically will need to be altered to properly reflect the pellet structure of the fuel rods in a prismatic core. Rankine power-cycle systems also need to be produced and ready for use.

\section{COMPRESSED AIR ENERGY STORAGE 3.1 Model Development}

\subsubsection{CAES Technology Background}

CAES is a technology that stores potential energy by compressing air during time when electricity production is greater than the demand. This compressed air can be stored in large reservoirs and can be used to generate additional power via a gas turbine during peak electricity demands. A CAES system mainly includes a compressor train, air reservoir, motor and generator, and a turbine. Most designs also have a combustor, but there are a few designs that work on a fuel-free principle. Figure 19 shows a simplified schematic of a CAES system with a combustor.

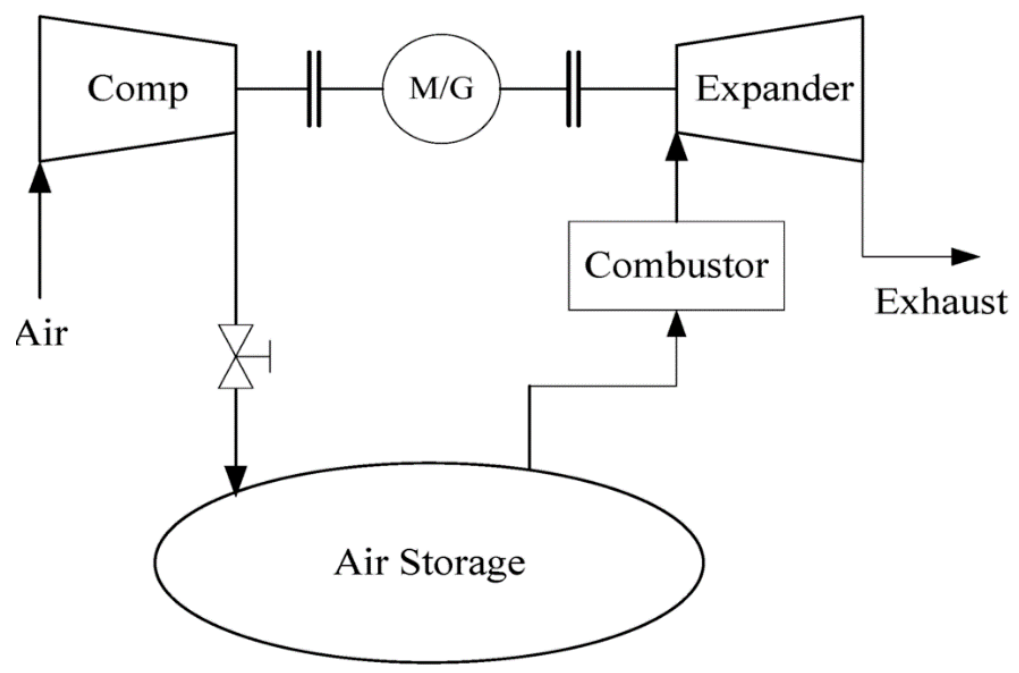

Figure 19. Schematic of a CAES power plant [8].

The CAES technology, along with pumped-hydro is one of the largest energy storage technologies that has been deployed to date. The first commercial CAES plant was the Huntorf plant in Germany which could produce $290 \mathrm{MW}$ for 2 hours discharge and started its operation in 1978 [9]. It has since been modified to produce up to $320 \mathrm{MW}$ with a round trip efficiency of $42 \%$. The other large-scale CAES plant in McIntosh, Alabama has a rated power of $110 \mathrm{MW}$. This plant made improvements to the Huntorf design by incorporating a recuperator to preheat the air leaving the cavern using waste heat from the turbines. Despite there being a significant amount of research being conducted in the various types of CAES systems such as diabatic, adiabatic, and isothermal, there has not been a large-scale deployment of this technology. However, with the rapid addition of intermittent renewable energy sources such as wind and solar to the grid, CAES is being perceived as key enabler towards the development of a hybrid energy grid system. 


\subsubsection{Primary Model Design}

As mentioned earlier, the main components of the CAES technology are the compressor, reservoir, motor generator, and the turbine. Although several steady-state models for CAES have been developed in the past, there are very few models that focus on the dynamic behavior of the turbomachinery involved. To simplify the analysis, the model was broken down into two parts depending on whether it was operating in charging mode or discharging mode. During the charging cycle, only the compressor and air storage volume play a major role; whereas, during the discharging cycle, turbine, storage volume, and generator are involved.

Modeling the dynamic behavior of turbomachinery accurately is critical towards the development of a CAES system model. The most common way is to use performance data specific to the turbomachine, which can be acquired either from the manufacturer or by using compressor and turbine performance maps. These performance maps provide the relationship between flow rate, pressure ratio, and efficiency for a specific turbomachine. Examples of a compressor and a turbine performance map are shown in Figure 20 and Figure 21, respectively.

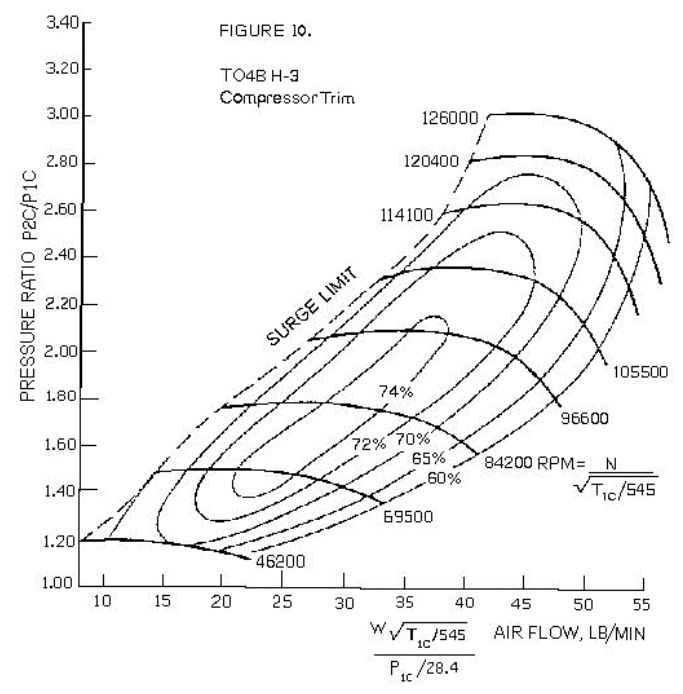

Figure 20. Compressor performance map with efficiency contours [10]. 

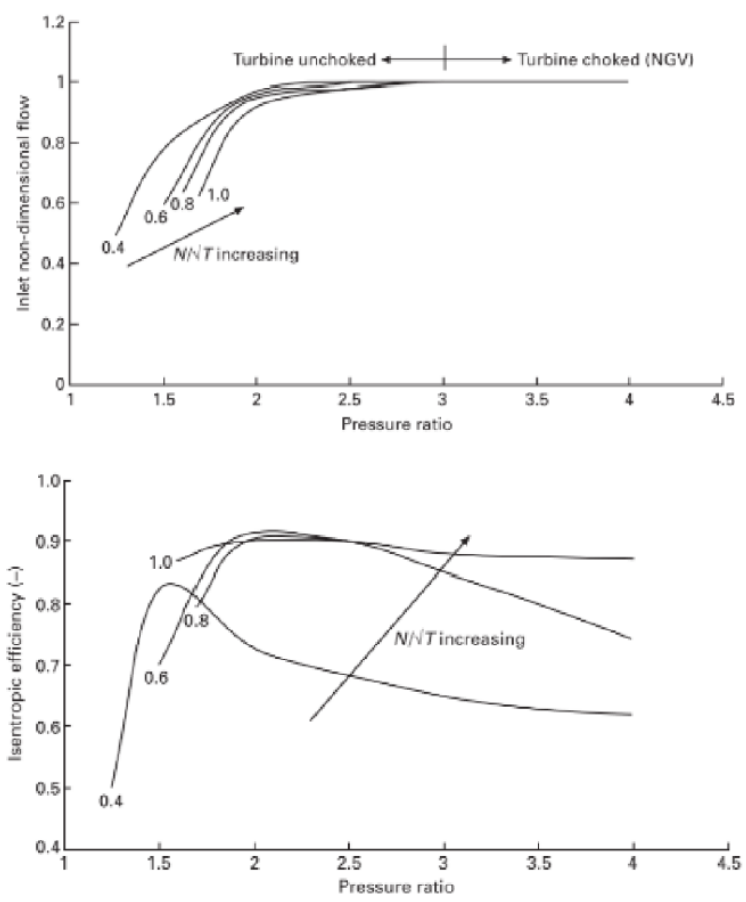

Figure 21. Example of a turbine performance map [11].

There are several methods of reading the turbomachinery maps; however, the most common method is the beta lines method developed by Kurke [12]. In this method, equally spaced parabolic or straight lines are created that cover the operating region of the turbomachine. Knowing the equations of these lines, they can be used to create lookup tables for the turbomachinery map data. Using an initial guess value for angular speed and pressure ratio, the appropriate beta value is calculated and corrected. With the correct beta line value, the corresponding mass flow rate and efficiency are found using interpolation based on the lookup tables.

The ThermoPower library consists of turbomachinery models based on this beta lines method. The models have default compressor and turbine performance data form a manufacturer, but this can be modified to suit the requirements of the user. A simplified model for the charging process was developed using this compressor and is shown in Figure 22. Herein, a compressor is connected to a pressure and temperature source boundary on one end and a volume of $10 \mathrm{~m} 3$ via a pipe on the other. The pressure and temperature boundary source represents an atmospheric input to the compressor; whereas, the volume represents the storage cavern. A torque input drives the compressor shaft, thereby causing air to flow into the volume and pressurizing it during the charging cycle. 


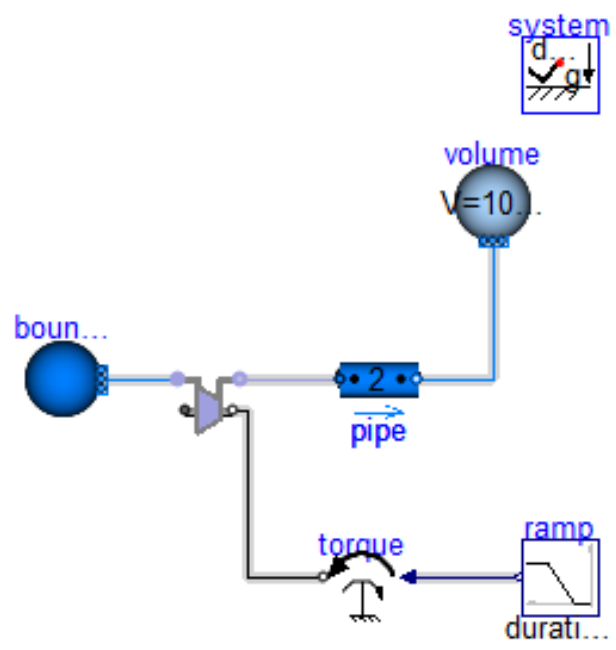

Figure 22. Simplified Modelica model of a CAES charging cycle.

\subsection{CAES Preliminary Results}

For the simplified CAES model, a charging cycle was run by setting the shaft torque to $100 \mathrm{~N}-\mathrm{m}$ for a period of $200 \mathrm{~s}$. The results from this simulation are provided below. Figure 23 shows the performance of the storage volume in relation its pressure, storage mass, and mass flow rate into the system.
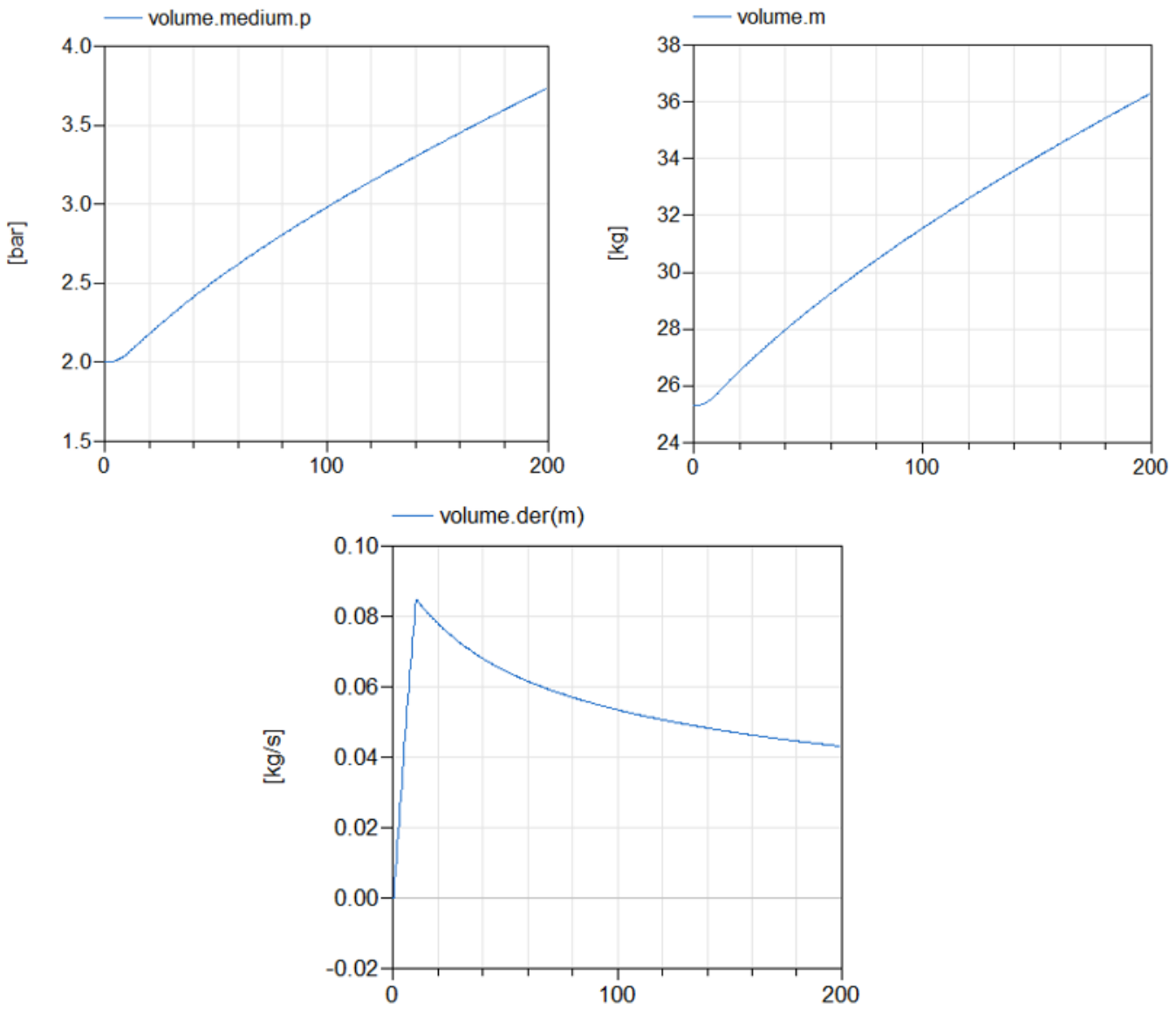

Figure 23. Storage volume pressure, mass increase, and rate of change of mass flow. 
It is evident that over time, as the mass into the storage volume increases, its corresponding pressure also increases. An increase in pressure also results in the reduction in mass flow rate into the volume. This is expected due to the increase in volume pressure (back pressure on the compressor outlet) drives the compressor towards the maximum pressure ratio point (surge limit). The behavior of the compressor can be interpreted from its characteristic plots in Figure 24. The plots describe the pressure ratio (i.e., the ratio of the outlet to inlet pressures across the compressor), compressor power, and constant torque applied to the compressor over the period of $200 \mathrm{~s}$. It can be seen in the plot that as the pressure in the storage volume increases, which corresponds to the back pressure on the compressor, the pressure ratio across the compressor also increases. This pressure ratio can only increase up to a theoretical maximum pressure ratio, after which the compressor experiences unstable flow due to surging.

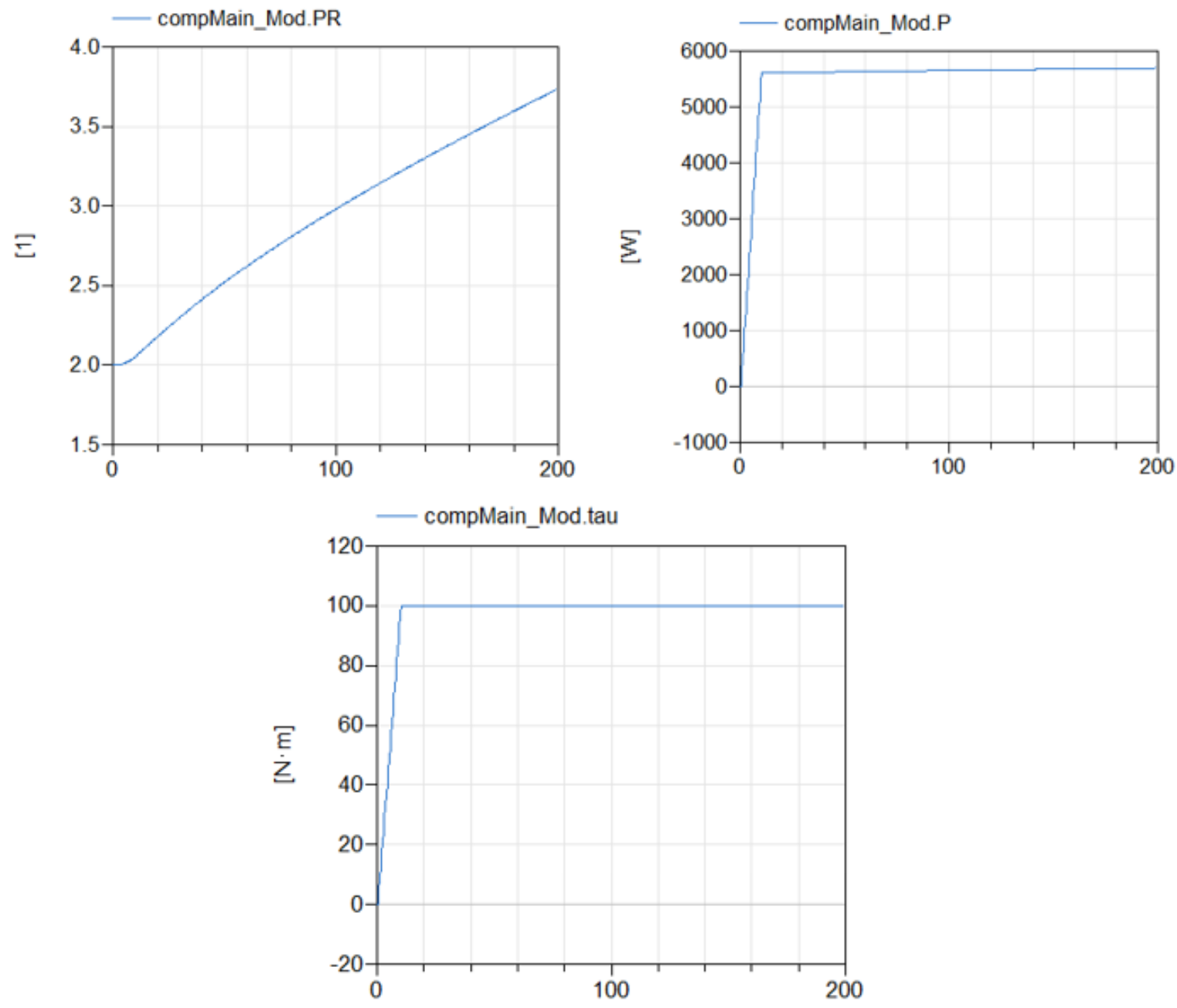

Figure 24. Performance characteristics of compressor-pressure ratio, power, and applied torque.

\subsection{Additional Planned Work}

It can be seen from the plots that the simplified CAES model works as expected during the charge cycle. However, adjustments to the compressor model are needed to ensure that the compressor operates independently over the entire operating range at different design speeds. For the next iteration, a discharge cycle connected to the volume will be modeled to understand the behavior of the turbine. Once that is accomplished successfully, both the cycles - charging and discharging - will be combined into a single model, to be operated with appropriate control mechanisms to distinguish between the different modes. Furthermore, once the charging and discharging cycles operate as expected, the compressor and 
turbine parameters will be scaled to match the performance characteristics of components used in the Huntorf power plant. This will ensure that the model is validated.

\section{LIQUID AIR ENERGY STORAGE}

LAES is an energy storage technology using the Claude process to liquefy air, store this air in tanks, and then use heat to expand the air through turbines to produce power on demand. The use of liquid air was first proposed by at the University of New Mexico and tested by Mitsubishi Industries in late 1990s as an extension of CAES [11].

Presently, there is a "grid-level" (5 MWe/15 MWh) LAES plant commissioned by Highview Power that began operation in April 2018 in England [11]. Figure 25 shows a high-level diagram of a Highview Power process. Highview Power published that their systems can produce from 10-200 MWe and store 40-2000 MWh. Their designs using waste heat claim 70\% round trip efficiency (RTE) for AC-to-AC power. Because the power production is based on gas expansion through the Brayton cycle, increased heat input should result in higher efficiencies. While Highview Power's designs include cold storage for continued use in the plant, if a source of waste cold is available, 100\% AC-to-AC power efficiency can be achieved due to a reduction in refrigeration needs during the liquefaction process [14].

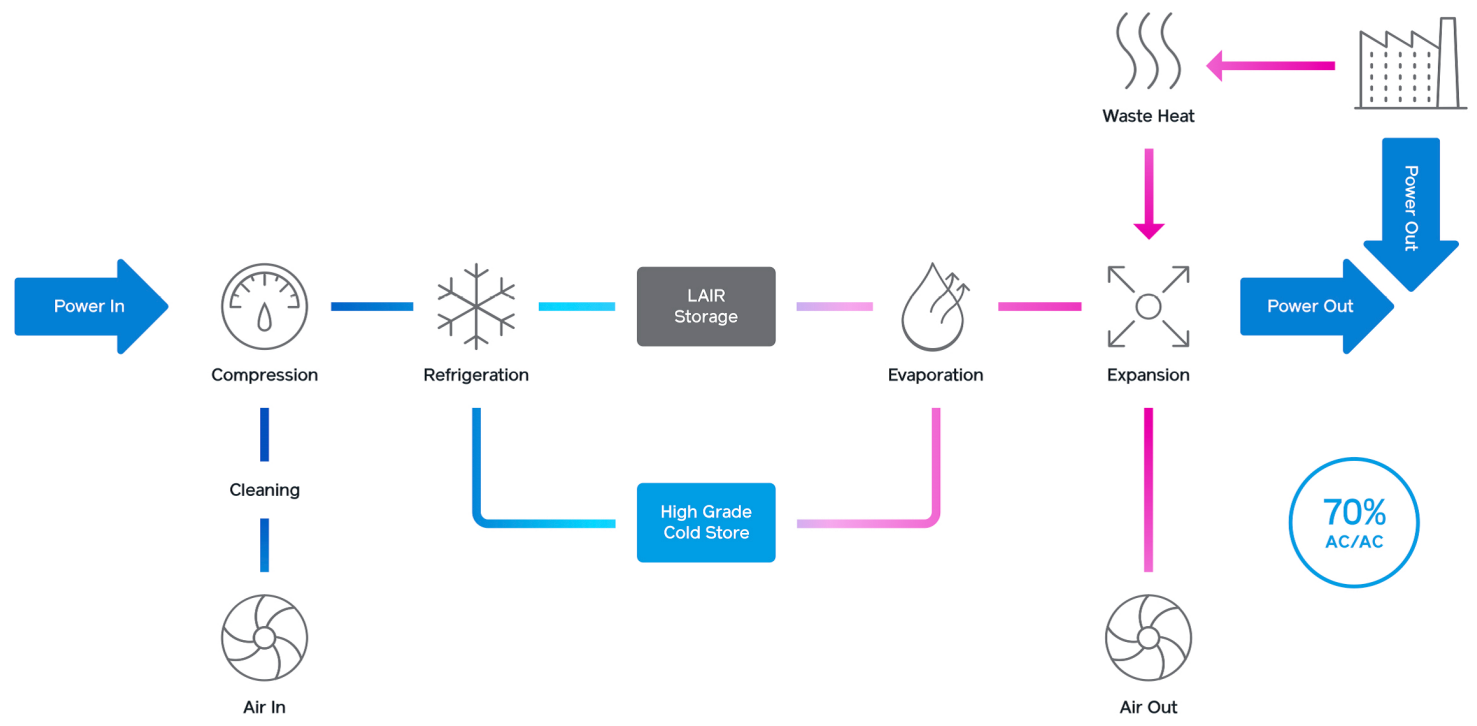

Figure 25. High-level diagram of Highview Power LAES system.

The initial pilot plant by Highview Power achieved just an $8 \%$ efficient cycle. At the time, the highest maximum efficiency predicted for the "best build" was approximately $60 \%$ [15]. One study further investigating potential LAES arrangements researched the impact of a cold box storage on the system. Using ambient heating while discharging and obtaining some power out of the system via a cryoturbine, they computed a potential efficiency of $56.3 \%$ [16]. By introducing nuclear topping heat, it is possible to achieve a theoretical 71.3\% RTE [17]. Specific LAES configurations can cause efficiencies to vary between $68-90 \%$. Efficiency variations for individual designs depend on assumptions, which can cause as much as $20 \%$ change [18].

Efforts to understand the IES impact that such systems can have initial model development has commenced. This section serves to report on these efforts.

\subsection{Model Development}

To enhance overall system efficiency LAES systems incorporate preheating, precooling, alongside hot and cold stores as shown in Figure 26. This represents a stand-alone LAES system that incorporates a 
hot storage, cold storage, charge cycle, and discharge cycle. This process diagram will be used as the baseline from which the Modelica models will be constructed. Once operational and able to match the process setpoints laid out in this journal paper, control systems will be added to integrate and understand the dynamic response of these systems.

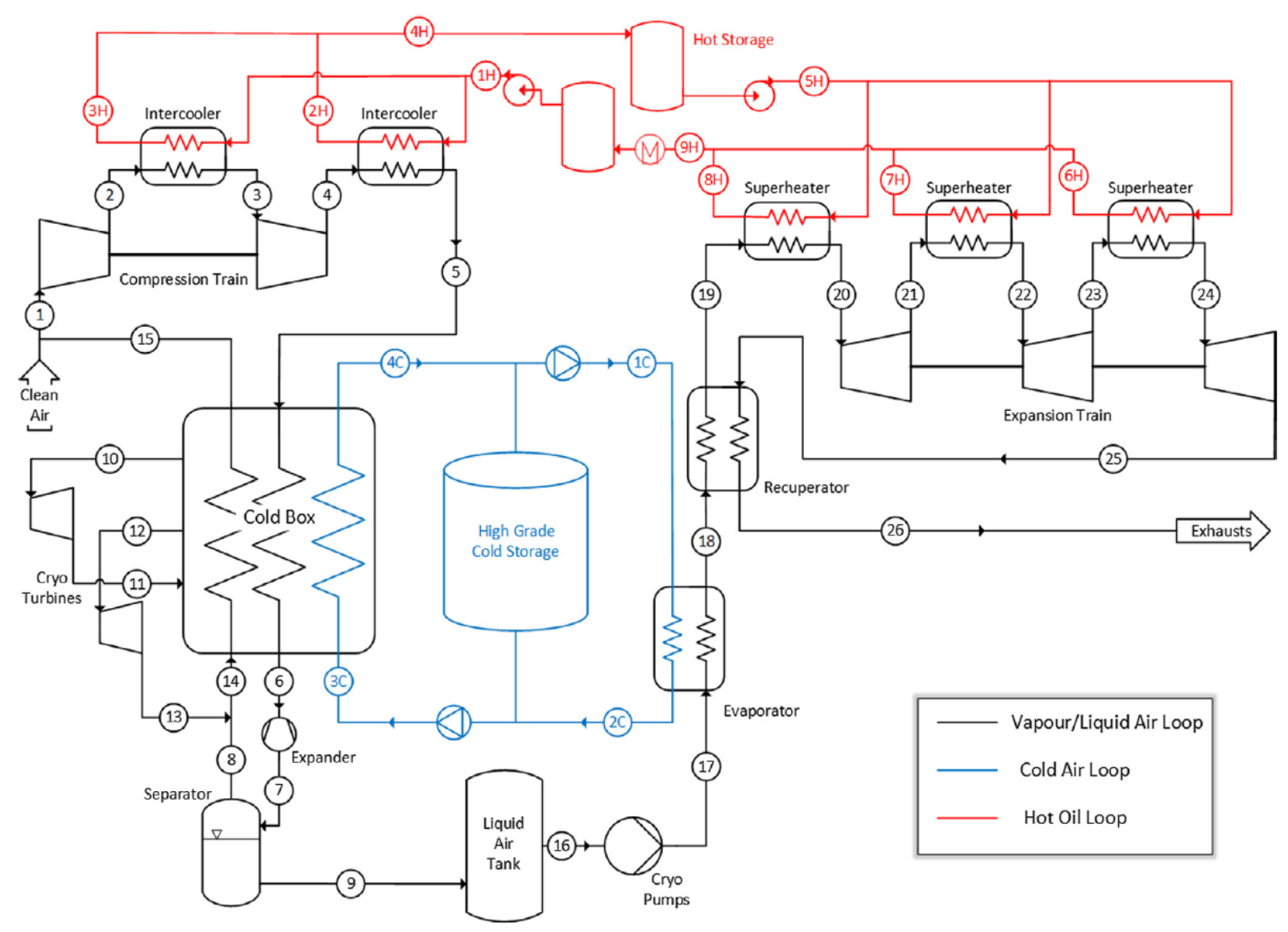

Figure 26. Stand-alone LAES plant [11].

The first portion of the process modeled was the charging process. This process includes the compression, intercooling, liquification, separation, and storage of the air from a gaseous phase to the liquid phase. To properly model this phase transition a new property package interconnection with Dymola was required. Traditional property packages within the Modelica standard library were insufficient to meet the demands of the air changing phase from gas to liquid and back to gas. Instead, a connection with the opensource CoolProp [19] library was required. CoolProp is a C++ library that implements material packages for different fluids using state-of-the-art property packages. The library features a Modelica friendly wrapper that allows for the execution of properties within the Dymola platform and will be added to the requirements list of Hybrid for execution of the LAES modules.

The charge loop involves the compression of air from approximately 1 bar to over 185 bar with intercooling chambers to remove heat from the air. Then the low-temperature, high-pressure air is expanded over a Joules-Thompson valve to liquify a portion of the air. Now a two-phase mixture, the airt is then sent to a separation chamber that removes the liquid from the gaseous air. This process has been modeled as shown in Figure 27. The separation chamber is modeled as an ideal separation unit with a specified separation efficiency that can be modulated to simulate various separation technologies. 


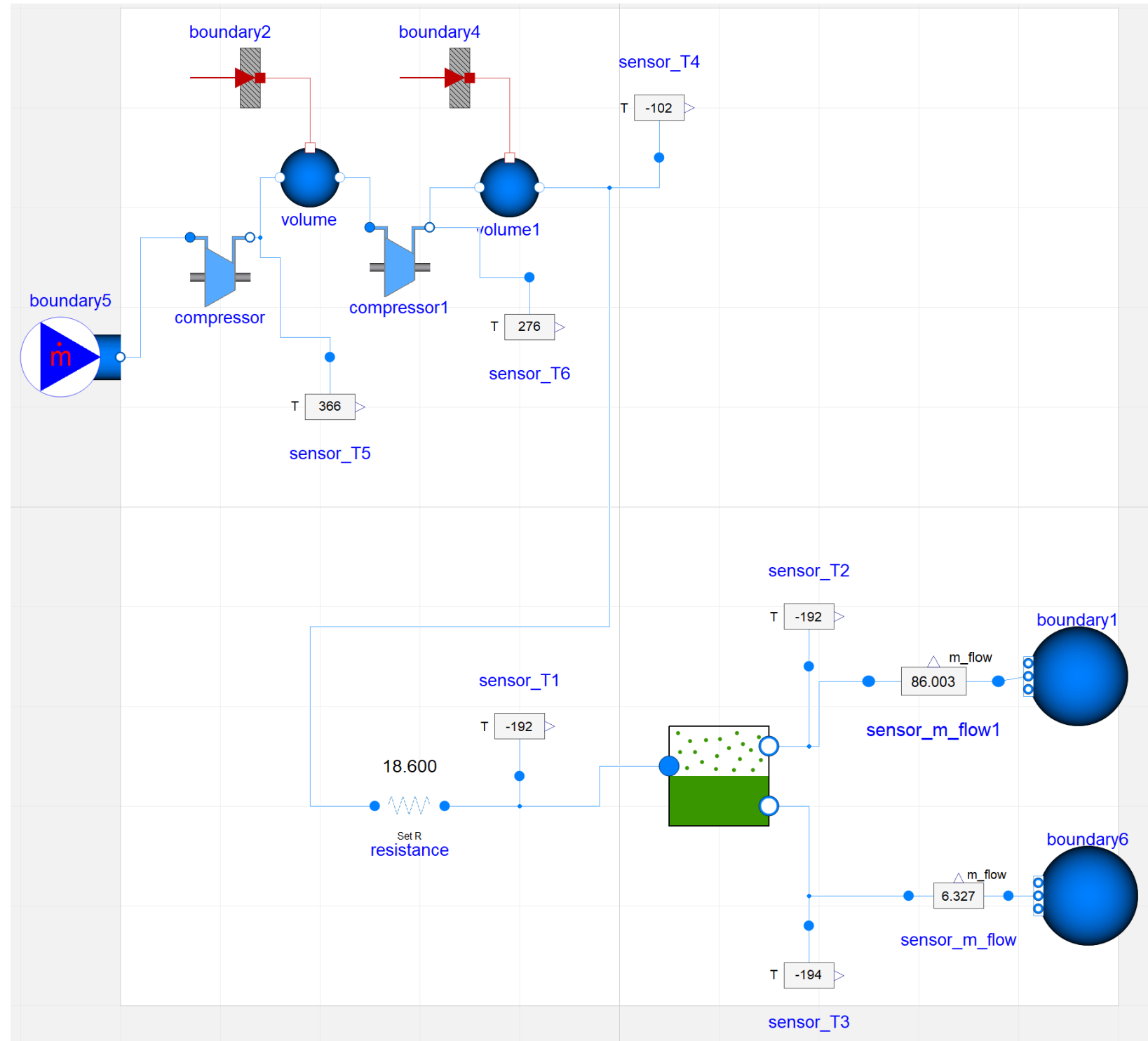

Figure 27. Charging loop including liquification and separation.

The discharge loop involves gasification of the liquid air through preheaters followed by a series of expansion turbines with reheaters. This process has been modeled as shown in Figure 28. The models assume a set amount of reheat is placed in each stage, and this is a controllable parameter that will be added to the overall coupled control scheme of the LAES unit. 


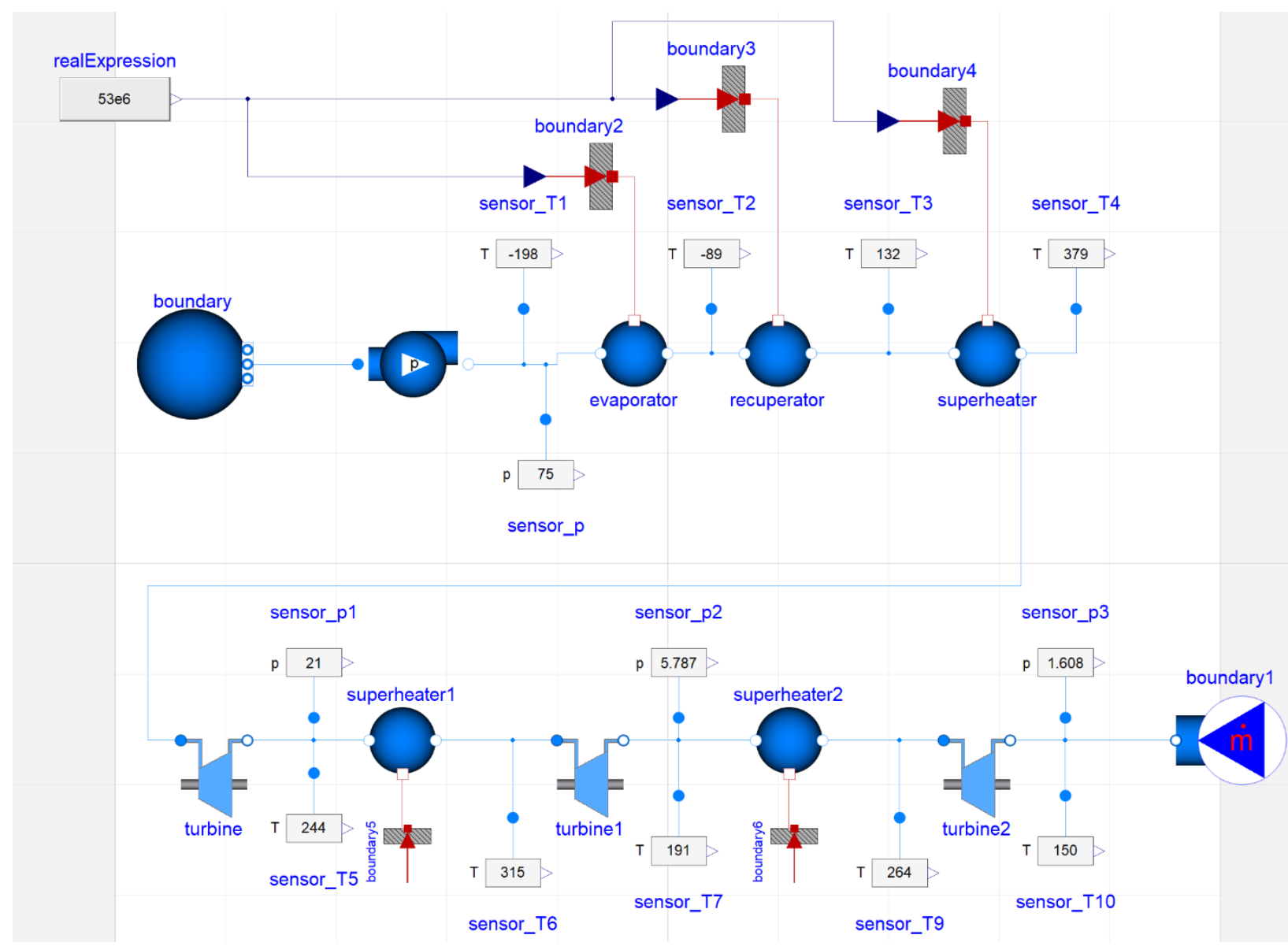

Figure 28. Discharge loop.

The thermal oil loop is responsible for the preconditioning of air through both the reheaters and intercoolers in the charge and discharge loops. To accommodate this, the thermal oil loop operates with a two-tank system where one tank stores high-temperature fluid used for gasification, and the other tank is kept at a lower temperature to be used in the intercooling process during system charge. To model these operations, the thermal oil loop has been split up into both the hot tank loop and the cold tank loop as shown in Figure 29. 


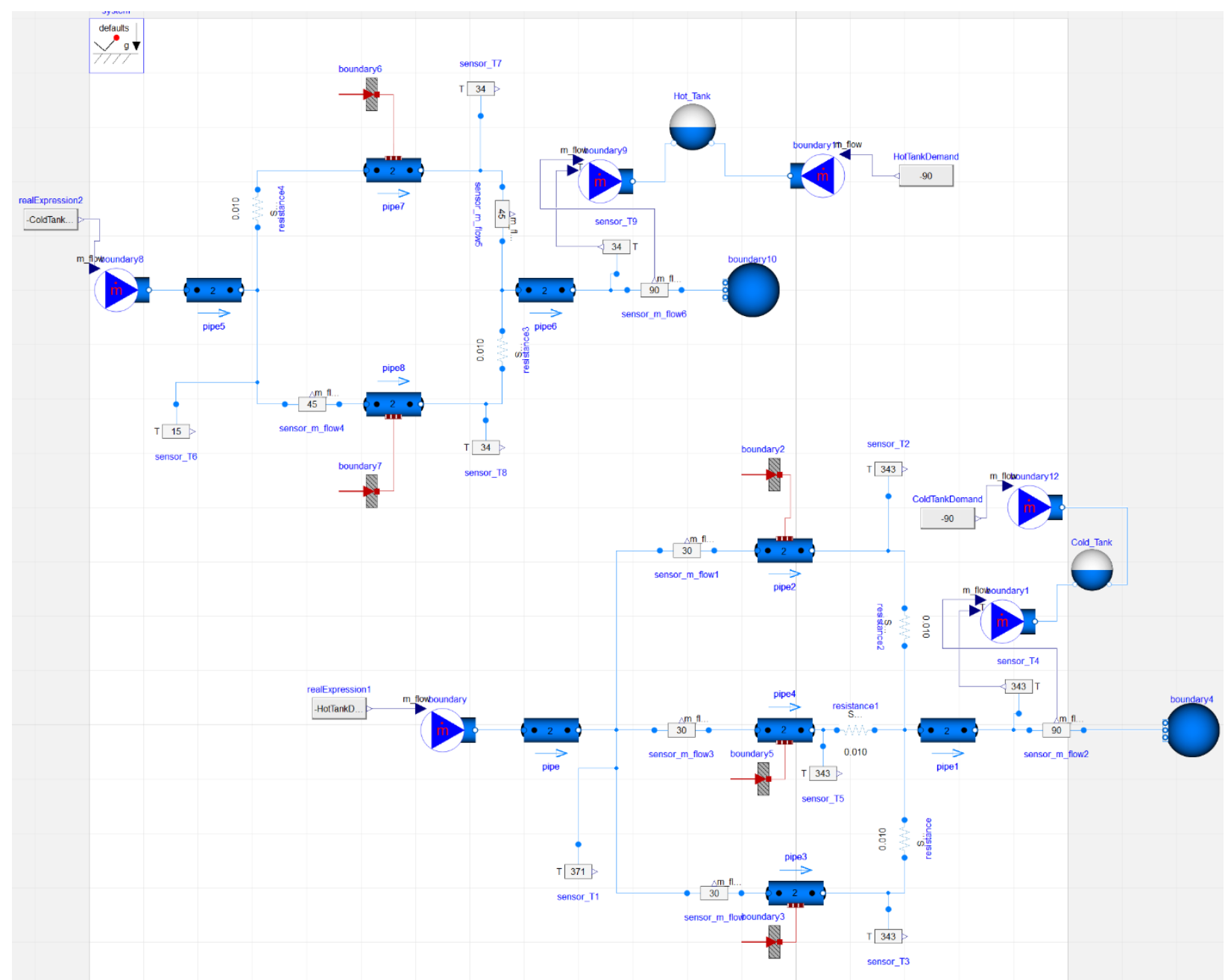

Figure 29. Thermal oil loop used to precondition air in both the charge and discharge cycle.

Initial results have demonstrated the capability of the loops to match results from [11]. Additional work will be focused on the coupling of these different loops into a single unified controllable process. Further, the cold box and hot box fidelities will be adjusted to meet the dispatch fidelity required for the problems being solved.

\section{CONCRETE THERMAL ENERGY STORAGE}

Some updates on the concrete thermal energy storage model will be reported in this milestone [20]. Previous work discussed the development of single- and dual-network pipe concrete models. These continue to be the two models in use for our research purposes. The dual-network model is the preferred model because it has a relatively simpler control structure (since charging and discharging fluids operate completely independently of each other) and its operation requires fewer flow reversals, which leads to more consistent simulation times. The final reason for the dual-network model being used is the fluid conditions of the discharge are more constant, which was demonstrated in a paper undergoing revisions submitted to Energy Storage.

The final model structure is represented by Figure 30 and Figure 31. Figure 30 shows the nodalization scheme used in the final model. Concentric finite volumes are modeled equally going from the cold pipe to the hot pipe. Figure 31 shows where the borders of each system would be repeated. In this single pipe network model, the boundary is an adiabatic boundary condition. In the dual pipe network, the boundary 
heat calculation accommodates the cross-sectional area at that point, and no adiabatic boundary condition exists (except axially, which is currently used in both models).

The model is constructed to be used for various IES studies, using replaceable media packages for both heat transfer fluids and concrete packages.
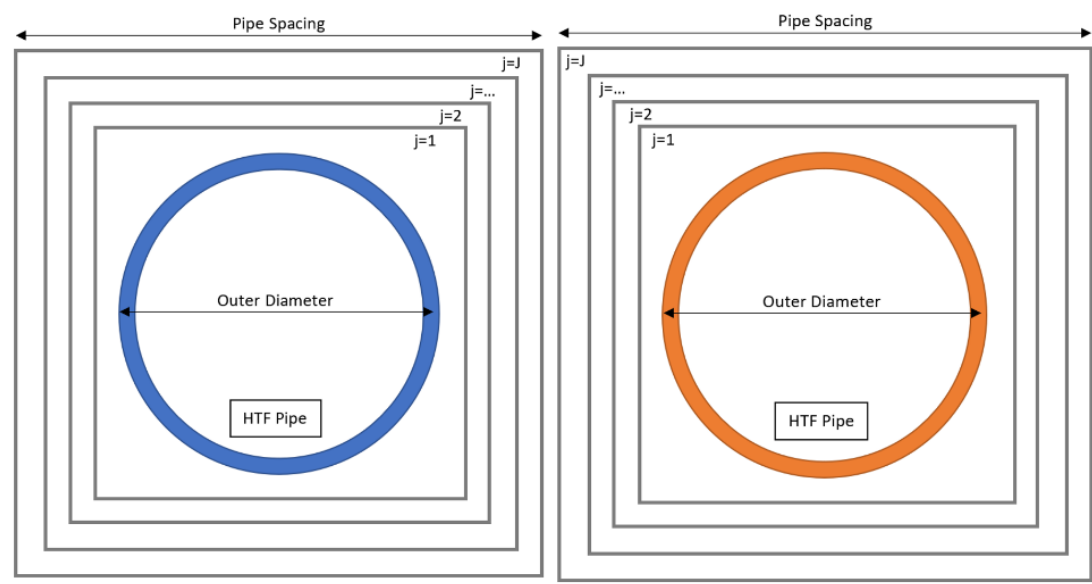

Figure 30. Nodalization diagram of dual concrete model where one flow direction is indicated by the blue pipe and the other flow direction by the orange pipe. The single-pipe model uses only one of those two diagrams.
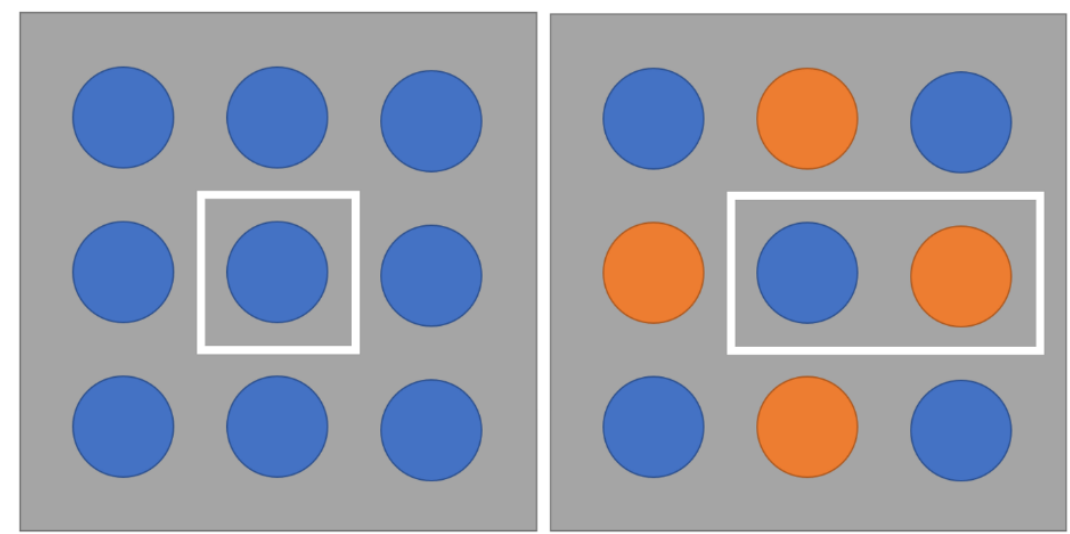

Figure 31. Square-grid configuration for single-network flow (left) and dual-network flow (right). Circles of same color indicate same flow direction. White square indicates section(s) modeled in Figure 30.

\section{CONCLUSIONS}

This report has detailed the ongoing progress and future direction for additions to the Hybrid repository within FORCE. These tasks continue to support the goals and mission of the IES program at INL, developing programmatic capability to model and understand a variety of potential deployment arrangements of IES. The HTGR, LAES, CAES, and CTES models have progressed to varying degrees of readiness for use in IES studies. Modelers believe that development is proceeding at a rate that will lead to completion of programmatic requirements.

\section{ACKNOWLEDGEMENTS}

This work was supported by the Integrated Energy Systems program at Idaho National Laboratory under DOE Operations contract number DE-AC07-05ID14517. 


\section{REFERENCES}

1. Department of Energy. n.d. "Energy Storage Grand Challenge." Accessed November 16, 2021. https://www.energy.gov/energy-storage-grand-challenge/energy-storage-grand-challenge.

2. Dassault Systems. n.d. "DYMOLA Systems Engineering." Accessed November 16, 2021. https://www.3ds.com/products-services/catia/products/dymola.

3. Modelica Association. "Modelica Standard Library." Accessed November 16, 2021. https://github.com/modelica/Modelica.

4. Greenwood, M.S. 2017. "TRANSFORM - TRANsient Simulation Framework of Reconfigurable Models. Computer Software." Github. Accessed on December 2, 2021. https://github.com/ORNLModelica/TRANSFORM-Library;

5. Stone \& Webster Engineering Corp. 1986. "Preliminary Safety Information Document for the Standard MHTGR.” DOE/HTGR-86-024-Vol.1, Department of Energy.

6. Skerjanc, W., J. Maki, B. Collin, and D. Petti. 2016. "Evaluation of Design Parameters for TRISOcoated Fuel Particles to Establish Manufacturing Critical Limits Using PARFUME." INL/JOU-15-34392, Idaho National Laboratory.

7. International Atomic Energy Agency Technical Committee. 2000. "Gas turbine power conversion systems for modular HTGRs." IAEA-TECDOC-1238, International Atomic Energy Agency.

8. Liu, W., L. Liu, G. Xu, F. Liang, Y. Yang, W. Zhang, and Y. Wu. 2014. "A Novel Hybrid-Fuel Storage System of Compressed Air Energy for China.” Energies 7(8): 4988-5010. https://doi.org/10.3390/en7084988.

9. Jafarizadeh, H., M. Soltani, and J. Nathwani. 2020. "Assessment of the Huntorf compressed air energy storage plant performance under enhanced modifications." Energy Conversion and Management 209: 112662. https://doi.org/10.1016/i.enconman.2020.112662.

10. Estill, J. 2008. “Turbocharger Compressor Calculations.” Accessed November 2021. http://www.gnttype.org/techarea/turbo/turboflow.html.

11. Sciacovelli, A., A. Vecchi, and Y. Ding. 2017. "Liquid air energy storage (LAES) with packed bed cold thermal storage - From component to system level performance through dynamic modeling," Applied Energy 190: 84-98. https://doi.org/10.1016/j.apenergy.2016.12.118.

12. Razak, A. M. Y. 2007. Industrial Gas Turbines: Performance and Operability. Amsterdam: Elsevier.

13. Kurzke, J. 1996. "How to Get Component Maps for Aircraft Gas Turbine Performance Calculations." Paper presented at ASME 1996 International Gas Turbine and Aeroengine Congress and Exhibition, 5: 96-GT-164, V005T16A001. https://doi.org/10.1115/96-GT-164.

14. Highview Power. 2019. "Plants." Accessed December 2, 2021. https://www.highviewpower.com/plants.

15. Morgan, R., S. Nelmes, E. Gibson, and G. Brett. 2015. "Liquid air energy storage - Analysis and first results from a pilot scale demonstration plant," Applied Energy 137: 845-853. https://doi.org/10.1016/j.apenergy.2014.07.109.

16. Peng, H., X. Shan, Y. Yang, and X. Ling. 2018. "A study on performance of a liquid air energy storage system with packed bed units." Applied Energy 211: 126-135. https://doi.org/10.1016/j.apenergy.2017.11.045.

17. Li, Y., D. Li, H. Cao, X. Wang, S. Wang, Y. Jin, and Y. Ding. 2014. "Load shifting of nuclear power plants using cryogenic energy storage technology." Applied Energy 1710-1716.

https://doi.org/10.1016/j.apenergy.2013.08.077. 
18. Antonelli, M., S. Barsali, U. Desideri, R. Giglioli, F. Paganucci, and G. Pasini. 2017. "Liquid air energy storage: Potential and challenges of hybrid power plants." Applied Energy 194: 522-529, May 2017. https://doi.org/10.1016/j.apenergy.2016.11.091.

19. Bell, I. H., J. Wronski, S. Quoilin, and V. Lemort. 2014. "Pure and Pseudo-Pure Fluid Thermophysical Property Evaluation and the Open-Source Thermophysical Property Library Coolprop." Industrial and Engineering Chemistry Research 53(6): 2498-2508. https://doi.org/10.1021/ie4033999.

20. Mikkelson, D., K. Frick, C. Rabiti, S. Bragg-Sitton. 2021. "Thermal Energy Storage Model Development within the Integrated Energy Systems HYBRID Repository.” INL/EXT-21-61985, Idaho National Laboratory. 